\title{
Perindopril: the evidence of its therapeutic impact in hypertension
}

\author{
Andrew Thomson, Mary Greenacre
}

Core Medical Publishing, Knutsford, UK

\begin{abstract}
Introduction: Effective antihypertensive therapy reduces the risk of cardiovascular and cerebrovascular disease and death. Perindopril, a long-acting angiotensin-converting enzyme (ACE) inhibitor, is an established antihypertensive agent administered as a once-daily tablet.
\end{abstract}

Aims: To review recent evidence for the use of perindopril in the treatment of hypertension.

Evidence review: Evidence shows that perindopril alone or in combination with other antihypertensive agents can achieve clinically significant reductions in blood pressure after 12 weeks of treatment. There is strong evidence from large randomized studies that perindopril-based therapy reduces the risk of cardiovascular outcomes, including mortality, in patients with coronary artery disease and those who have had a prior stroke or transient ischemic attack. There is also some evidence that these effects are greater than those achieved by blood pressure reduction alone, suggesting other drug-related effects including improvements in endothelial function. Recent results have also shown that an amlodipine \pm perindopril regimen prevented more major cardiovascular events than an atenolol-based regimen in patients with hypertension, as a result of better control of blood pressure. Economic evidence from one major study shows that, for most patients, the incremental cost per quality-adjusted life-year gained with perindopril 8 mg was lower than the threshold value of $€ 20000$ (73-92\% of patients) in Europe or $£ 20000$ (94\% of patients) in the UK.

Clinical value: There is strong evidence supporting the use of perindopril-based therapy for the treatment of hypertension and reduction in the risk of cardiovascular disease, stroke, and death in a wide range of patients with stable coronary artery disease or hypertension.

Key words: coronary artery disease, evidence-based review, hypertension, perindopril

\section{Core evidence clinical impact summary for perindopril in hypertension}

\begin{tabular}{|lll|}
\hline Outcome measure & Evidence & Implications \\
\hline $\begin{array}{l}\text { Patient-oriented evidence } \\
\text { Reduction in cardiovascular mortality }\end{array}$ & Clear & Control of blood pressure reduces risk of death \\
$\begin{array}{l}\text { Avoidance of cardiovascular events } \\
\text { (MI, CHF) }\end{array}$ & Clear & Control of blood pressure reduces risk of comorbidities \\
$\begin{array}{l}\text { Avoidance of cerebrovascular } \\
\text { events (stroke) }\end{array}$ & Moderate & Reduced risk of subsequent stroke, disability, and dependence \\
$\begin{array}{l}\text { Effective as single daily dosing } \\
\text { Disease-oriented evidence }\end{array}$ & Clear & Convenient administration as monotherapy or combination \\
$\begin{array}{l}\text { Clinically significant reduction in } \\
\text { systolic and diastolic blood pressure }\end{array}$ & Clear & \\
$\begin{array}{l}\text { Improvement in endothelial dysfunction } \\
\text { Economic evidence }\end{array}$ & Limited & Sufficient control for avoiding cardiovascular and cerebrovascular events \\
Cost effectiveness & Perindopril may have antiatherosclerotic properties in addition to \\
\hline CHF, congestive heart failure; Ml, myocardial infarction. & antihypertensive effects \\
\hline
\end{tabular}




\section{Scope, aims, and objectives}

Hypertension is a major but modifiable contributory factor in cardiovascular diseases (CVDs) such as stroke and coronary heart disease (CHD). As such, hypertension is one of the most important preventable causes of premature death in both developed and developing regions (Ezzati et al. 2002).

Several classes of antihypertensive drug are currently available for the management of hypertension including diuretics and beta blockers and newer agents such as calcium channel blockers (CCBs) and angiotensin-converting enzyme (ACE) inhibitors. Perindopril $\left(\right.$ Aceon ${ }^{\circledR}$, Coversyl ${ }^{\circledR}$ ) is a long-acting lipophilic ACE inhibitor developed for treating hypertension. The main goal of antihypertensive treatment is not to reduce blood pressure per se, but to prevent complications associated with hypertension such as cardiovascular and cerebrovascular disease, reduce mortality, and improve quality of life. The aim of this article is to review the evidence for the clinical impact of perindopril in the treatment of hypertension and reduction of associated complications.

\section{Methods}

English language medical literature databases were searched for appropriate articles relating to the treatment of hypertension and symptomatic heart failure with perindopril. A literature search was conducted on October 3, 2005 using the search terms "perindopril AND hypertension" for articles published between January 1990 and September 2005 (inclusive):

- PubMed, http://www.ncbi.nlm.nih.gov/entrez

- EMBASE, http://www.datastarweb.com

- BIOSIS, http://www.datastarweb.com

- Database of Abstracts of Reviews of Effects (DARE), http://www.york.ac.uk/inst/crd/darehp.htm

- Cochrane Database of Systematic Reviews (CDSR), http://www.cochrane.org/index0.htm

- Clinical Evidence (BMJ), http://www.clinicalevidence.com

- National Institute for Health and Clinical Excellence (NICE), http://www.nice.org.uk

- National Guideline Clearinghouse, http://www.guideline.gov

Four sets of current clinical guidelines were identified and after removing duplicates a total of 318 articles (full publications and meetings abstracts identified using the above databases) were retrieved and any animal, in-vitro, and non-English-language articles were excluded. An updated search using the same terms was performed in September 2006; this search identified six additional articles to be included.

Table 1 summarizes the levels of evidence of the 33 articles (guidelines excluded) selected from the 324 articles identified by
Table 1 | Evidence base included in the review

\begin{tabular}{|lcc|}
\hline Category & \multicolumn{2}{c|}{ Number of records } \\
\cline { 2 - 3 } & Full papers & Abstracts \\
\hline Initial search & 268 & 50 \\
records excluded & 245 & 46 \\
records included & 23 & 4 \\
Search update, new records & 5 & 1 \\
Additional studies identified & 0 & 1 \\
Level 1 clinical evidence & 1 & 0 \\
Level 2 clinical evidence & 18 & 2 \\
Level $\geq 3$ clinical evidence & 9 & 2 \\
trials other than RCT & 0 & 0 \\
case studies & 0 & 0 \\
Economic evidence & 0 & 2 \\
Total records & 28 & 6 \\
\hline For definition of levels of evidence, see Editorial Information on inside back cover. \\
RCT, randomized controlled trial.
\end{tabular}

the search strategy. One systematic review and meta analysis was identified for inclusion; most of the evidence base comprised level 2 clinical evidence. One meeting abstract reporting economic evidence was found. In addition, one further article (a meeting abstract reporting economic evidence) was provided by the manufacturer (Servier) on January 13, 2006 and included. Therefore a total of 34 articles were included in the final evidence base.

\section{Disease overview}

Hypertension is a chronic, age-related disorder which may lead to serious and disabling cardiovascular, cerebrovascular, and renal complications. The consensus definition of hypertension is blood pressure of $\geq 140 / 90 \mathrm{mmHg}$ [i.e. either systolic blood pressure $(\mathrm{SBP}) \geq 140 \mathrm{mmHg}$ or diastolic blood pressure (DBP) $\geq 90 \mathrm{mmHg}$ ] in adults over 18 years of age (Chobanian et al. 2003; ESH/ESC 2003; NICE 2006; Williams et al. 2004).

Hypertension is the most common primary diagnosis in the USA with 35 million office visits each year and it accounts for about $20 \%$ of family practitioners' annual consultations in the UK (Chobanian et al. 2003; NICE 2006). More than $60 \%$ of Americans aged 65 years and older have hypertension and estimates of the cost of its treatment range from \$US7 billion to \$US14 billion per year (Fischer \& Avorn 2004). It was estimated that the total number of adults worldwide with hypertension in 2000 was 972 million; 333 million in economically developed countries and 639 million in developing countries (Kearney et al. 2005). Thus almost a quarter of the world's adult population were judged to have hypertension in 2000; by 2025 this proportion is 
Table 2 | Thresholds for initiating antihypertensive treatment in nondiabetic patients according to current guidelines

\begin{tabular}{|c|c|c|c|}
\hline Guideline & $\begin{array}{l}\text { SBP } \geq 140-159 \mathrm{mmHg} \text { or } \\
\mathrm{DBP} \geq 90-99 \mathrm{mmHg}\end{array}$ & $\begin{array}{l}\mathrm{SBP} \geq 160 \mathrm{mmHg} \text { or } \\
\mathrm{DBP} \geq 100 \mathrm{mmHg}\end{array}$ & Reference \\
\hline JNC-7 & Treat with single drug or combination & Treat with two-drug combination & Chobanian et al. 2003 \\
\hline $\mathrm{ESC} / \mathrm{ESH}$ & $\begin{array}{l}\text { Monitor and consider treatment in } \\
\text { low-/moderate-risk patients. Treat high/ } \\
\text { very-high-risk patients }\end{array}$ & $\begin{array}{l}\text { Treat all patients with BP } \\
>180 / 110 \mathrm{mmHg}\end{array}$ & ESC/ESH 2003 \\
\hline $\mathrm{BHS}$ & $\begin{array}{l}\text { Treat if patients also have } 10 \text {-year CVD } \\
\text { risk } \geq 20 \% \text { or existing CVD or target } \\
\text { organ damage, otherwise observe and } \\
\text { reassess annually }\end{array}$ & Treat all patients & Williams et al. 2004 \\
\hline NICE & $\begin{array}{l}\text { Treat if patients also have raised CV } \\
\text { risk ( } 10 \text {-year risk of } C H D \geq 15 \% \text { or CVD } \\
\text { risk } \geq 20 \% \text { or existing CVD or target } \\
\text { organ damage) }\end{array}$ & Treat all patients & NICE 2006 \\
\hline
\end{tabular}

predicted to reach $29 \%$ (affecting 1.56 billion adults) assuming that country-, age-, and gender-specific prevalence estimates remain constant.

The most common form of hypertension, essential or primary hypertension, has no single identifiable cause. However, the inability of the kidney to excrete sodium at normal blood pressure plus contributions from the central nervous system, endocrine factors, large arteries, and the microvasculature all have roles in the development of this disorder (Staessen et al. 2003).

Although it is only one of several risk factors for CVD (Padwal et al. 2001), hypertension increases an individual's risk of various cardiovascular complications [e.g. stroke, congestive heart failure (CHF), CHD] approximately two- to three-fold. Furthermore, hypertension is implicated in $35 \%$ of all atherosclerotic cardiovascular events including $49 \%$ of all cases of heart failure (Padwal et al. 2001). As blood pressure increases so does the risk of myocardial infarction (MI), stroke, heart failure, and renal disease. For example, between the ages of 40-69 years each difference of $20 \mathrm{mmHg}$ from usual SBP (or $10 \mathrm{mmHg}$ from usual DBP) is associated with double the death rate from stroke, ischemic heart disease, or other vascular causes (Lewington et al. 2002).

Estimates of CVD risk are most accurate when major risk factors are evaluated using risk functions derived from epidemiologic studies (e.g. Framingham risk function) (Williams et al. 2004). These risk factors should be considered in conjunction with blood pressure levels in determining appropriate treatment for patients with hypertension. Examples of thresholds for initiating treatments according to blood pressure and CVD risk factors outlined in current guidelines are summarized in Table 2.

Since it is a significant modifiable risk factor for CVD, a number of large studies have shown that the burden of hypertension can be addressed by successful reductions in blood pressure. Treatment with any commonly used antihypertensive regimen reduces the risk of total major cardiovascular events, and larger reductions of blood pressure achieve larger reductions in risk (Turnbull 2003). For example, the Hypertension Optimal Treatment (HOT) trial showed that intensive lowering of blood pressure in patients with hypertension was associated with a lower rate of cardiovascular events (Hansson et al. 1998). The lowest incidence of major cardiovascular events occurred at a mean achieved DBP of $82.6 \mathrm{mmHg}$ and the lowest incidence of cardiovascular mortality occurred at $86.5 \mathrm{mmHg}$. In addition, antihypertensive therapy has been shown to be associated with mean reductions of $35-40 \%$ in the incidence of stroke, $20-25 \%$ reductions in $\mathrm{Ml}$, and more than $50 \%$ reduction in heart failure (Neal et al. 2000).

The Heart Outcomes Prevention Evaluation (HOPE) studies have also provided evidence that treatment with an ACE inhibitor (ramipril) reduces cardiovascular event rates in a high-risk population (Yusuf et al. 2000). In over 9000 high-risk patients [ $>55$ years old with a history of previous stroke, peripheral vascular disease, coronary artery disease (CAD), or diabetes, plus other risk factors] active therapy for a mean of 5 years reduced the combined rate of cardiovascular death, MI, and stroke by $22 \%(P<0.001)$. Active treatment also reduced the rates of death from cardiovascular causes by $26 \%$, the risk of $\mathrm{Ml}$ by $20 \%$, and the risk of stroke (all $P<0.001$ ). These outcomes were achieved with a modest reduction in blood pressure (SBP/DBP reduction $3.3 / 2.0 \mathrm{mmHg}$ ).

\section{Current therapy options}

The goal of antihypertensive therapy is the long-term reduction of cardiovascular morbidity and mortality. In patients with hypertension, the optimal blood pressure treatment goal is SBP $<140 \mathrm{mmHg}$ and DBP $<90 \mathrm{mmHg}$; for diabetic patients with hypertension the target blood pressure goal is SBP $<130 \mathrm{mmHg}$ and DBP $<80 \mathrm{mmHg}$ (Chobanian et al. 2003; ESH/ESC 2003; Williams et al. 2004). Drug-based and nondrug therapies may be used to achieve these goals.

It is beyond the scope of this article to review all the current agents and recommendations for the treatment of hypertension, 
Table 3 | Physicochemical and pharmacologic characteristics of various ACE inhibitors (reprinted from Am J Cardiol, 88, Dzau et al. The relevance of tissue angiotensin-converting enzyme: manifestations in mechanistic and endpoint data, pp.11-20L. Copyright 2001, with permission from Elsevier)

\begin{tabular}{|c|c|c|c|c|}
\hline Active drug & Tissue potency rank ${ }^{a}$ & $\begin{array}{l}\text { ACE inhibitor potency, } \\
\text { ID }_{50}\left(\mathrm{mmol} / \mathrm{L} \times 10^{-9}\right)\end{array}$ & Plasma half-life (h) & Relative lipophilicity ${ }^{b}$ \\
\hline Quinaprilat & $=1$ & 0.07 & 25 & ++ \\
\hline Benazeprilat & $=1$ & NA & 11 & + \\
\hline Ramiprilat & 3 & 0.08 & $>50$ & ++ \\
\hline Perindoprilat & 4 & 0.40 & 10 & ++ \\
\hline Lisinopril & 5 & NA & 12 & NA \\
\hline Enalaprilat & 6 & 1.00 & 11 & + \\
\hline Fosinoprilat & 7 & NA & 11.5 & +++ \\
\hline Captopril & 8 & 15.00 & 2 & + \\
\hline
\end{tabular}

and comprehensive guidelines have recently been published for the USA (Chobanian et al. 2003), UK (NICE 2006; Williams et al. 2004), and Europe (ESH/ESC 2003). However, there are several classes of drug commonly used to control hypertension and these include thiazide-type diuretics, CCBs, beta blockers, angiotensin receptor blockers (ARBs), and ACE inhibitors. The choice of drug depends on the individual patient's clinical profile, but most patients will require combination therapy (Chobanian et al. 2003; Williams et al. 2004).

The foundation of successful management of high blood pressure is the adoption and adherence to healthy lifestyles in all patients with hypertension. Lifestyle modifications can reduce the need for drug therapy or may complement the efficacy of existing drug regimens, and can have a favorable influence on overall CVD risk (Chobanian et al. 2003; ESH/ESC 2003; NICE 2006; Williams et al. 2004). However, changes to lifestyle alone are rarely sufficient for the long-term control of hypertension.

Low-dose combination therapy is increasingly being recommended in national and international guidelines for initial treatment of hypertension (de Leeuw 2001). The most important reason to combine two or more classes of antihypertensive drug is to obtain enhanced blood pressure control with good tolerability. In addition, a combination of drugs is likely to be of greater benefit when one drug avoids or counteracts compensatory mechanisms elicited by the other drug (de Leeuw 2001). However, not all combinations of drug are effective or well tolerated. Typical combinations of drugs include an ACE inhibitor with a CCB or a diuretic, an ARB with a diuretic, and a beta blocker with a diuretic (Chobanian et al. 2003).

\section{Unmet needs}

Although control rates for hypertension have improved, about $30 \%$ people in the USA are still unaware that they may be hypertensive, partly because of its asymptomatic nature
(Chobanian et al. 2003). In addition, substantial underdiagnosis, undertreatment, and poor rates of control exist in the UK (Williams et al. 2004). The serious consequences of failure to control hypertension are well understood.

Nonadherence to therapy is a major contributor to poor control. Because of the lack of symptoms, patients may misunderstand the nature of the condition and the necessary treatment and may perceive the need for medication as a symbol of ill health. In addition, tolerability issues can influence drug compliance. Management of other comorbidities, common in older patients and in those with other risk factors, will likely involve treatment with other medications and the burden of polypharmacy or reduced tolerability through interactions cannot be discounted. Therefore, a treatment that is convenient to administer (ideally once daily), is well tolerated (in combination with other antihypertensives and additional medications), and is effective in reducing hypertension and related morbidity and mortality, is likely to be beneficial in addressing the undermanagement of this condition.

ACE inhibitors are the only class of antihypertensive agent for which there is clear evidence of benefit for all the comorbid conditions listed in the JNC-7 (Seventh Report of the Joint National Committee on Prevention, Detection, Evaluation, and Treatment of High Blood Pressure) guidelines (i.e. heart failure, post-MI, high coronary disease risk, diabetes, chronic kidney disease, and recurrent stroke prevention) (Chobanian et al. 2003). NICE guidelines recommend an ACE inhibitor as first-line antihypertensive drug therapy in patients aged under 55 years (NICE 2006). The choice of ACE inhibitor depends on a number of factors, including frequency of dosing as influenced by peak-trough ratio (Anon. 1997), and the ability to inhibit tissue ACE (Dzau et al. 2001).

Perindopril is an ester prodrug of the ACE inhibitor perindoprilat that may be administered orally once daily because of its very high peak-trough ratio ( $>50 \%$ for doses $\geq 4 \mathrm{mg}$; reviewed in 
Hurst \& Jarvis 2001). It has been shown that the relative tissue affinity and lipophilicity of perindoprilat compares favorably with other ACE inhibitors (Table 3). Perindopril has been shown to effectively inhibit tissue ACE activity from endothelia and adventitia (the connective tissue surrounding arteries and organs) (Zhou et al. 2002). Although it is generally accepted that endothelial ACE is an important target for efficacy of any ACE inhibitor, inhibition of adventitial ACE may be just as relevant, particularly in the management of hypertension, heart failure, and/or ischemic heart disease (Zhou et al. 2002). Therefore, perindopril appears to fulfill a number of pharmacodynamic criteria for an antihypertensive agent to support the effective treatment of this condition.

\section{Clinical evidence with perindopril}

\section{Control of hypertension}

The clinical use of perindopril in controlling hypertension has been studied in great detail for over 15 years and its effects have been reviewed extensively (Lerebours \& Antony 1994; Hurst \& Jarvis 2001; Oparil 2001). Much of the existing evidence demonstrating the antihypertensive effect of perindopril has been based on randomized controlled trials that can be found in the aforementioned reviews. This section will evaluate outcomes from systematic reviews, large open-label community and postmarketing studies that have been published more recently (i.e. since 2000). These studies confirm the existing evidence that perindopril reduces blood pressure when used as monotherapy as well as combination therapy (Table 4).

\section{Monotherapy}

There is clear evidence that perindopril given as monotherapy significantly reduces SBP and DBP (from baseline values) in patients with hypertension.

A large, open-label, postmarketing surveillance study in France involving patients with hypertension (DBP 95-114 mmHg) treated with perindopril $(2,4$, or $8 \mathrm{mg} /$ day) showed that blood pressure reduction was maintained after 1 year of treatment (Speirs et al. 1998). Mean blood pressure (SBP/DBP) fell from 173/100 $\pm 16.23 / 8 \mathrm{mmHg}$ in 47253 patients starting the study to $145 / 82 \pm 12.2 / 8 \mathrm{mmHg}$ in 46799 patients successfully completing treatment.

The efficacy of perindopril 4 and $8 \mathrm{mg}$ has been evaluated in a large, 12-week, community-based, open-label study involving 13220 patients with hypertension. All patients received perindopril $4 \mathrm{mg}$ for the first 6 weeks; the dose was titrated to $8 \mathrm{mg}$ after 6 weeks in inadequately responsive patients. From baseline to week 12, blood pressure was reduced significantly from 156.9/94.5 $\mathrm{mmHg}$ to $139.2 / 84.0 \mathrm{mmHg}$ (Julius et al. 2004). Blood pressure control was achieved in almost half $(48.8 \%)$ of all patients. In patients deemed inadequately responsive $(n=4154)$, dose titration to $8 \mathrm{mg}$ daily resulted in a clinically significant reduction in blood pressure and an increase in the proportion of patients achieving blood pressure control $(<140 / 90 \mathrm{mmHg})$ from $7.1 \%$ (at week 6) to $34.0 \%$ (by week 12).
A number of subpopulation analyses from this study showed that perindopril monotherapy was effective regardless of sex, age, and ethnicity (Cohn et al. 2004; Julius et al. 2004; Neutel et al. 2004). A further analysis looked at a subgroup of patients whose blood pressure was not controlled with previous antihypertensive therapy (Guo et al. 2004). Physicians assessed that $73.8 \%$ of patients in this population achieved a satisfactory therapeutic response from perindopril treatment (Guo et al. 2004).

\section{Combination therapy}

Although monotherapy is still the preferred option for the initial treatment of hypertension, most patients will at some stage need more than one drug to control their blood pressure. Indeed, low-dose combination therapy is becoming increasingly popular for initial treatment. Treatment adherence may be enhanced when the combination therapy is in a single dosage formulation, with obvious advantages for the practicing physician and patient (Williams et al. 2004). Perindopril has been formulated with indapamide (a nonthiazide sulfamoyl chlorobenzamide diuretic) as a combination treatment for hypertension. Part of the rationale for using this combination is that both components have a similar half-life, there is no pharmacokinetic interaction between them, and the combination can be formulated for administration as a once-daily tablet.

There is clear evidence from a meta analysis of 11 studies that the fixed low-dose combination of perindopril and indapamide given as one tablet daily is effective as first-line treatment for patients with mild-to-moderate hypertension (Table 4). The meta analysis showed that in five studies with the combination versus placebo, the between-group weighted mean differences (WMDs) for both SBP and DBP favored perindopril plus indapamide (SBP -9.03 mmHg; DBP -5.09 mmHg; both $P<0.01$ for $z$ score for overall effect). In these studies the rates of normalization and blood pressure response were $64.7-90.0 \%$ and $74.0-81.3 \%$, respectively, with treatment compared with $42.1-44.4 \%$ and 48.9\%, respectively, with placebo (Kang et al. 2004).

In the six studies of the combination versus other antihypertensive agents (e.g. perindopril monotherapy, perindopril plus low-salt diet, enalapril, losartan, atenolol, irbesartan) the between-group WMDs for both SBP and DBP also favored perindopril plus indapamide (SBP $-3.72 \mathrm{mmHg}, P=0.03$ for $z$ score for overall effect; DBP $-1.71 \mathrm{mmHg}, P<0.01$ for $\mathrm{z}$ score for overall effect). However, the test for heterogeneity of SBP and DBP was statistically significant between these different studies. Differences in design of the studies and measurement methods for blood pressure may have contributed to the heterogeneity (Kang et al. 2004).

A notable component trial of the meta analysis was the Perindopril pROtection aGainst REcurrent Stroke Study (PROGRESS) (PROGRESS 2001). One of the many outcomes from this large study involving 6105 patients (48\% were hypertensive) was a reduction in blood pressure. After 4 years of treatment with a perindopril-based regimen (i.e. perindopril plus indapamide at the physician's discretion), blood pressure was reduced by $9 / 4 \mathrm{mmHg}$ compared with placebo treatment. When compared with placebo, the reduction in blood pressure was greater among those treated 
Table 4 | Effect of perindopril on blood pressure in patients with hypertension

\begin{tabular}{|c|c|c|c|c|c|c|}
\hline \multirow{2}{*}{$\begin{array}{l}\text { Level of } \\
\text { evidence }\end{array}$} & \multirow[t]{2}{*}{ Reference } & \multirow[t]{2}{*}{ Design } & \multirow{2}{*}{$\begin{array}{l}\text { Treatment and } \\
\text { mean dose }\end{array}$} & \multicolumn{3}{|c|}{ Outcome } \\
\hline & & & & SBP & DBP & $\begin{array}{l}\text { BP control } \\
(<140 / 90 \mathrm{mmHg})\end{array}$ \\
\hline 1 & $\begin{array}{l}\text { Kang et al. } \\
2004\end{array}$ & $\begin{array}{l}\text { Systematic review } \\
\text { and meta analysis } \\
\text { of } 11 \text { RCTs ( } 5936 \\
\text { patients) }\end{array}$ & $\begin{array}{l}\text { PER ( } 2-4 \mathrm{mg}) \text { plus IND } \\
(0.625-1.25 \mathrm{mg}) \text { as one } \\
\text { daily tablet vs PLA } \\
\text { (five studies) } \\
\text { PER ( } 2-4 \mathrm{mg}) \text { plus IND } \\
(0.625-1.25 \mathrm{mg}) \text { as one } \\
\text { daily tablet vs routine } \\
\text { AH therapies }^{\text {a }} \\
\text { (six studies) }\end{array}$ & $\begin{array}{l}\text { Between-group WMDs } \\
\text { favored PER plus IND } \\
-9.03 \mathrm{mmHg}(95 \% \mathrm{Cl}-9.54 \text {, } \\
-8.52), P<0.01 \text { for overall } \\
\text { effect } \\
\text { Between-group WMDs } \\
\text { favored PER plus IND } \\
-3.72 \mathrm{mmHg}(95 \% \mathrm{Cl}-7.11 \text {, } \\
-0.33), P=0.03 \text { for overall } \\
\text { effect }\end{array}$ & $\begin{array}{l}\text { Between-group WMDs favored } \\
\text { PER plus IND }-5.09 \mathrm{mmHg} \\
(95 \% \mathrm{Cl}-5.42,-4.77), P<0.01 \\
\text { for overall effect } \\
\text { Between-group WMDs favored } \\
\text { PER plus IND }-1.71 \mathrm{mmHg} \\
(95 \% \mathrm{Cl}-2.27,-1.16), P<0.01 \\
\text { for overall effect }\end{array}$ & - \\
\hline 2 & $\begin{array}{l}\text { Asmar et al. } \\
2001\end{array}$ & $\begin{array}{l}\text { RCT including } 471 \\
\text { patients with } \\
\text { hypertension }\end{array}$ & $\begin{array}{l}\text { PER }(2 \mathrm{mg}) \text { plus IND } \\
(0.625) \text { as one daily } \\
\text { tablet vs ATL } \\
50 \mathrm{mg} / \text { day }\end{array}$ & $\begin{array}{l}22.0 \pm 15.6 \mathrm{mmHg} \text { reduction of } \\
\text { brachial BP with PER plus } \\
\text { IND vs } 15.0 \pm 16.3 \mathrm{mmHg} \\
\text { reduction with ATL }\end{array}$ & $\begin{array}{l}12.6 \pm 8.9 \mathrm{mmHg} \text { reduction of } \\
\text { brachial BP with PER plus IND } \\
\text { vs } 12.0 \pm 9.8 \mathrm{mmHg} \text { reduction } \\
\text { with ATL }\end{array}$ & - \\
\hline 2 & $\begin{array}{l}\text { PROGRESS } \\
2001\end{array}$ & $\begin{array}{l}\text { RCT including } \\
6105 \text { patients ( } 48 \% \\
\text { hypertensive) with } \\
\text { prior stroke or TIA }\end{array}$ & $\begin{array}{l}\text { PER ( } 4 \mathrm{mg} / \mathrm{d} \text {, all } \\
\text { patients) plus IND } \\
(2-2.5 \mathrm{mg} / \mathrm{d} \text {, } \\
58 \% \text { patients) vs PLA } \\
\text { Mean follow-up } 3.9 \text { y }\end{array}$ & $\begin{array}{l}9.0 \pm 0.3 \mathrm{mmHg} \text { reduction with } \\
\text { active treatment vs PLA } \\
12.3 \pm 0.5 \mathrm{mmHg} \text { reduction } \\
\text { with PER plus IND vs PLA } \\
4.9 \pm 0.6 \mathrm{mmHg} \text { reduction with } \\
\text { PER alone vs PLA }\end{array}$ & $\begin{array}{l}4.0 \pm 0.2 \mathrm{mmHg} \text { reduction with } \\
\text { active treatment vs PLA } \\
5.0 \pm 0.3 \mathrm{mmHg} \text { reduction with } \\
\text { PER plus IND vs PLA } \\
2.8 \pm 0.3 \mathrm{mmHg} \text { reduction with } \\
\text { PER alone vs PLA }\end{array}$ & - \\
\hline 2 & $\begin{array}{l}\text { Mourad } \\
\text { et al. } 2004\end{array}$ & $\begin{array}{l}\text { 9-month parallel } \\
\text { group study } \\
\text { including } \\
533 \text { patients } \\
\text { with hypertension }\end{array}$ & 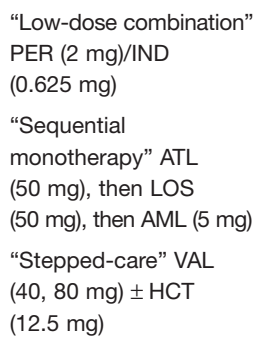 & - & - & $\begin{array}{l}\text { More patients } \\
\text { achieved target } \\
\text { blood pressure } \\
\text { with the "low-dose } \\
\text { combination" } \\
(62 \%) \text { than with } \\
\text { "sequential therapy" } \\
\text { (49\%, P=0.02) and } \\
\text { "stepped care" } \\
(47 \%, P=0.004)\end{array}$ \\
\hline 3 & $\begin{array}{l}\text { Speirs } \\
\text { et al. } 1998\end{array}$ & $\begin{array}{l}47351 \text { patients in } \\
1-y \text { postmarketing } \\
\text { study }\end{array}$ & $\begin{array}{l}\text { PER }(2,4 \text {, or } 8 \mathrm{mg} / \mathrm{d}) \\
\text { for } 1 \mathrm{y}\end{array}$ & $\begin{array}{l}\text { Change over } 1 \text { y from } \\
173 \pm 16.3 \text { to } 145 \pm 12.2 \mathrm{mmHg}\end{array}$ & $\begin{array}{l}\text { Change over } 1 \text { y from } 100 \pm 8 \text { to } \\
82 \pm 8 \mathrm{mmHg}\end{array}$ & - \\
\hline 3 & $\begin{array}{l}\text { Cohn et al. } \\
2004^{\text {b }}\end{array}$ & $\begin{array}{l}1412 \text { African- } \\
\text { American patients } \\
\text { with hypertension }\end{array}$ & $\begin{array}{l}\text { PER ( } 4 \text { or } 8 \mathrm{mg} / \mathrm{d} \text { ) } \\
\text { for } 12 \mathrm{w}\end{array}$ & $\begin{array}{l}\text { Mean decrease from baseline } \\
14.4 \text { and } 18.2 \mathrm{mmHg}(P<0.001 \\
\text { vs baseline }) \text { after } 12 \mathrm{w} \text { for } \\
\text { African-Americans and white } \\
\text { patients, respectively }\end{array}$ & $\begin{array}{l}\text { Mean decrease from baseline } \\
9.1 \text { and } 10.6 \mathrm{mmHg} \\
(P<0.001 \text { vs baseline) after } 12 \mathrm{w} \\
\text { for African-Americans and white } \\
\text { patients, respectively }\end{array}$ & $\begin{array}{l}\text { Achieved in } 38.9 \% \\
\text { of African-Americans } \\
\text { and } 50.2 \% \text { white } \\
\text { patients by w } 12\end{array}$ \\
\hline 3 & $\begin{array}{l}\text { Guo et al. } \\
2004^{\text {b }}\end{array}$ & $\begin{array}{l}3159 \text { patients } \\
\text { lacking BP control } \\
\text { from previous } \\
\text { AH therapy }\end{array}$ & $\begin{array}{l}\text { PER ( } 4 \text { or } 8 \mathrm{mg} / \mathrm{d} \text { ) } \\
\text { for } 12 \mathrm{w}\end{array}$ & $\begin{array}{l}\text { Mean }( \pm \text { SE) decrease from } \\
\text { baseline } 14.9( \pm 0.4) \mathrm{mmHg} \\
(P<0.001 \text { vs baseline) by w } 12\end{array}$ & $\begin{array}{l}\text { Mean }( \pm S E) \text { decrease from } \\
\text { baseline } 8.4( \pm 0.2) \mathrm{mmHg} \\
(P<0.001 \text { vs baseline) by w } 12\end{array}$ & $\begin{array}{l}\text { Achieved in } 40 \% \text { of } \\
\text { patients by w } 12\end{array}$ \\
\hline 3 & $\begin{array}{l}\text { Julius } \\
\text { et al. } 2004\end{array}$ & $\begin{array}{l}13220 \text { patients } \\
\text { with hypertension } \\
\text { in an OL, } \\
\text { FP-based CT }\end{array}$ & $\begin{array}{l}\text { PER }(4 \text { or } 8 \mathrm{mg} / \mathrm{d}) \\
\text { for } 12 \mathrm{w}\end{array}$ & $\begin{array}{l}\text { Mean decrease from baseline } \\
17.7 \mathrm{mmHg}(P<0.001) \text { after } \\
12 \mathrm{w}\end{array}$ & $\begin{array}{l}\text { Mean decrease from baseline } \\
10.5 \mathrm{mmHg}(P<0.001) \text { after } 12 \mathrm{w}\end{array}$ & $\begin{array}{l}\text { Achieved in } 48.8 \% \\
\text { of patients by w } 12\end{array}$ \\
\hline 3 & $\begin{array}{l}\text { Neutel et al. } \\
2004^{\text {b }}\end{array}$ & $\begin{array}{l}3010 \text { patients } \\
>65 \text { y with } \\
\text { hypertension }\end{array}$ & $\begin{array}{l}\text { PER ( } 4 \text { or } 8 \mathrm{mg} / \mathrm{d} \text { ) } \\
\text { for } 12 \mathrm{w}\end{array}$ & $\begin{array}{l}\text { Mean decrease from baseline } \\
18.4 \mathrm{mmHg}(P<0.001 \mathrm{vs} \\
\text { baseline }) \text { after } 12 \mathrm{w}\end{array}$ & $\begin{array}{l}\text { Mean decrease from baseline } \\
8.7 \mathrm{mmHg}(P<0.001 \text { vs baseline }) \\
\text { after } 12 \mathrm{w}\end{array}$ & $\begin{array}{l}\text { Achieved in } 41.4 \% \\
\text { of patients by w } 12\end{array}$ \\
\hline
\end{tabular}

aPerindopril monotherapy, perindopril plus low-salt diet, enalapril, losartan, atenolol, irbesartan; bSubstudy of Julius et al. 2004.

$\mathrm{AH}$, antihypertensive; AML, amlodipine; ATL; atenolol; BP, blood pressure; $\mathrm{Cl}$, confidence interval; $\mathrm{CT}$, clinical trial; d, day; DBP, diastolic blood pressure; FP, family practice;

HCT, hydrochlorothiazide; IND, indapamide; LOS, losartan; OL, open label; PLA, placebo; PER, perindopril; RCT, randomized controlled trial; SBP, systolic blood pressure; SE, standard error;

TIA, transient ischemic attack; VAL, valsartan; w, week; WMD, weighted mean difference; $y$, year. 
with the combination therapy $(12.3 / 5.0 \mathrm{mmHg})$ than those treated with perindopril alone $(4.9 / 2.8 \mathrm{mmHg})$.

The "low-dose combination" of perindopril $2 \mathrm{mg}$ and indapamide $0.625 \mathrm{mg}$ has also been shown to be more effective in achieving target blood pressure compared with two other strategies (Mourad et al. 2004). In the "sequential monotherapy" group, treatment was initiated with atenolol $50 \mathrm{mg}$, replaced if necessary by losartan $50 \mathrm{mg}$ and then by amlodipine $5 \mathrm{mg}$. Patients in the "stepped-care" group were randomized to valsartan $40 \mathrm{mg}$ (increased to $80 \mathrm{mg}$ if necessary) and with hydrochlorothiazide $12.5 \mathrm{mg}$ if needed. Significantly more patients treated with the "low-dose combination" (62\%) achieved the target blood pressure compared with "sequential monotherapy" (49\%, $P=0.02)$ and "stepped care" (47\%, $P=0.005)$. The "low-dose combination" was also significantly superior in achieving normal blood pressure without adverse events (56\%) than "sequential monotherapy" (42\%, $P=0.002)$ and "stepped care" (42\%, $P=0.004)$. Note that although the "low-dose combination" is available as a single preparation in many European countries it is not available in the USA.

One of the consequences of combination therapy with perindopril and indapamide is an amelioration of hemodynamic characteristics of hypertension during aging. For example, arterial stiffness leads to increasing pulse pressure with age, and this parameter is associated with an increased risk of CVD, particularly CHD. There is good evidence from a double-blind randomized study involving 471 hypertensive patients that for the same reduction in DBP, perindopril $2 \mathrm{mg}$ plus indapamide $0.625 \mathrm{mg}$ decreased brachial SBP and pulse pressure significantly more than atenolol $50-100 \mathrm{mg} /$ day alone (adjusted mean differences between groups $-6.2 \pm 1.5$ and $-5.5 \pm 1.0 \mathrm{mmHg}$, respectively; $P<0.001$ ) (Asmar et al. 2001). Perindopril plus indapamide-induced decreases in SBP and pulse pressure were associated with changes in arterial hemodynamics, including a decrease in aortic stiffness and limiting the effects of wave reflection on the blood pressure in central arteries. In contrast, arterial hemodynamics were less affected by atenolol as this treatment did not decrease wave reflections (Asmar et al. 2001).

In summary, the evidence clearly demonstrates that perindopril, used as monotherapy or in low-dose combination with indapamide, is able to achieve clinically effective reductions in blood pressure and control of hypertension.

\section{Prevention of cardiovascular events}

There is clear evidence from a number of large, well-designed, randomized, controlled studies [EURopean trial On reduction of cardiac events with Perindopril in stable coronary Artery disease (EUROPA), PROGRESS, and Anglo-Scandinavian Cardiac Outcomes Trial-Blood Pressure Lowering Arm (ASCOT-BPLA)] that perindopril treatment is associated with reductions in cardiovascular outcomes in a number of different patient populations and subgroups (Table 5).

Perindopril has been evaluated in one of the largest studies to assess the management of patients with stable CHD (Fox 2003).
Results from the study showed that perindopril treatment was associated with a statistically significant relative-risk reduction (RRR) of $20 \%(P=0.0003)$ in the composite primary endpoint (cardiovascular mortality, nonfatal MI, and successfully resuscitated cardiac arrest). The composite outcome was improved in patients of all ages, with and without hypertension, or previous history of MI. Treatment benefit was also seen in patients on existing lipid-lowering therapies as well as those taking beta blockers. Post-hoc analysis stratified patients into tertiles according to risk assessment based on the association of risk factors at baseline with occurrence of the primary composite endpoint (Deckers et al. 2006), and indicated that treatment benefit of perindopril was consistent regardless of absolute risk level.

When compared with placebo, secondary endpoints reduced with perindopril treatment included a $14 \%$ reduction $(P=0.0009)$ in total mortality, nonfatal $\mathrm{MI}$, unstable angina and cardiac arrest, and a $39 \%$ reduction $(P=0.002)$ in hospital admission for heart failure. In addition, the risk of $\mathrm{Ml}$ (fatal and nonfatal) was reduced by $24 \%$ by perindopril treatment. It was estimated that one major cardiovascular event would be prevented through treating 50 patients for 4 years with perindopril (Fox 2003).

Results from the diabetic substudy of EUROPA [PERindopril SUbstudy in coronary Artery disease and DiabEtes (PERSUADE)] showed that perindopril tended to reduce major cardiovascular events to a similar level to that seen in the overall EUROPA population (Daly et al. 2005). Because of the smaller patient population in the study, PERSUADE was not sufficiently powered to detect statistically significant differences between the placebo and active treatment groups. Nevertheless, the rates of major cardiovascular events in the diabetic population $(12.6 \%$ for perindopril vs $15.5 \%$ for placebo) was almost twice that of the overall study population $(7.4 \%$ for perindopril vs $9.0 \%$ for placebo) (Fox 2003). Thus, the high rate of events in the diabetic population means that a RRR in this population of similar magnitude to that in the overall population is associated with greater absolute risk reduction (Daly et al. 2005).

Patients with a history of stroke or transient ischemic attack (TIA) are also at risk from further cardiovascular (and cerebrovascular) events. PROGRESS was designed to determine the effect of a perindopril-based regimen in both hypertensive and nonhypertensive patients with a history of stroke or TIA (PROGRESS 2003a). Active treatment comprised a flexible regimen which included perindopril $4 \mathrm{mg}$ daily for all patients plus the addition of indapamide at the discretion of the physician. Of the total of 3051 patients randomized to active treatment, 1770 (58\%) received combination therapy, the remainder receiving perindopril monotherapy. There was a good balance between active treatment and placebo groups for all recorded characteristics at baseline. However, those patients for whom combination therapy or double placebo was planned tended to be younger, were more likely to be male, hypertensive, have CHD, and were recruited sooner after their qualifying cerebrovascular event than those for whom single active drug or single placebo was intended (PROGRESS 2003a). After 4 years of follow-up, active treatment reduced the risk of total major coronary events (nonfatal MI or death due from CHD) by $26 \%$ 


\section{Table 5 | Effect of perindopril in preventing cardiovascular events}

\begin{tabular}{|llll}
\hline Level of evidence & Reference & Design & Treatment and mean dose \\
\hline 2 & EUROPA & RCT including & PER (8 mg/d) vs PLA for 3 \\
& 2003 & $\begin{array}{l}12218 \text { patients with } \\
\text { stable CAD }\end{array}$ & Mean follow-up period 4.2
\end{tabular}

\section{Outcomes}

- PER treatment resulted in RRR of $20 \%$ (95\% Cl 9\%, 29\%; $P=0.0003$ ) in the composite primary endpoint (CV death, nonfatal $\mathrm{MI}$, and cardiac arrest with successful resuscitation)

- Outcome was improved in all age groups and among patients \pm hypertension, diabetes, or with previous $\mathrm{Ml}$

- Treatment benefit seen in patients taking beta blockers and lipid-lowering therapy

- PER treatment associated with $14 \%$ reduction in total mortality, nonfatal $\mathrm{MI}$, unstable angina, and cardiac arrest (95\% Cl 6\%, 21\%; $P=0.0009)$

- PER treatment reduced hospital admission by $39 \%$ (95\% Cl 17\%, 56\%; $P=0.002)$

PROGRESS RCT including 6105 $2003^{a} \quad$ patients with prior stroke or TIA
PER (4 mg/d, all patients) plus IND (2-2.5 mg/d, $58 \%$ patients) vs PLA Mean follow-up $3.9 \mathrm{y}$

- RRR for total coronary events $21 \%(95 \% \mathrm{Cl} 6 \%, 33 \%$; $P=0.008)$ with active treatment vs PLA

- RRR for major coronary events $26 \%$ (95\% Cl 6\%, 42\%; $P=0.02$ ) with active treatment vs PLA

- RRR for nonfatal MI 38\% (95\% Cl 14\%, 55\%) with active treatment vs PLA

- Risk of major coronary events reduced in both hypertensive and nonhypertensive patients

- PER plus IND reduced risk of major coronary event by $35 \%$ $(95 \% \mathrm{Cl} 12 \%, 52 \%)$; PER alone reduced risk of major coronary event by $7 \%(95 \% \mathrm{Cl}-37 \%, 38 \% ; P=0.2)$

- RRR for CHF 26\% (95\% Cl 5\%, 42\%; $P=0.02)$ with active treatment vs PLA

- PER plus IND reduced the risk of CHF by $34 \%(95 \% \mathrm{CI} 7 \%$, $53 \%)$ while PER alone reduced the risk of CHF by $16 \%$ $(95 \% \mathrm{Cl}-19 \%, 41 \% ; P=0.2)$

Arima et al. RCT including $2005^{\mathrm{b}} \quad 476$ patients with 476 patients with
prior stroke or TIA and $\mathrm{AF}$ at baseline

Sever et al.
2005

Dahlöf et al. 2005

RCT including 19257 patients with hypertension plus $\geq 3$ other $\mathrm{CV}$ risk factors (ASCOT-BPLA)

stable CAD

(PERSUADE)

RCT including
PER ( $4 \mathrm{mg} / \mathrm{d}$, all patients) plus IND (2-2.5 mg/d $58 \%$ patients) vs PLA Mean follow-up $3.9 \mathrm{y}$

\section{AML-based regimen}

(AML 5-10 mg \pm PER 4-8 mg) or ATL-based regimen (ATL 50-100 mg + BFZ 1.25-2.5 mg)
- Active treatment lowered mean BP by $7.3 / 3.4 \mathrm{mmHg}$

- Active treatment reduced major vascular events by $38 \%$ (95\% Cl 6\%, 59\%)

- AML-based regimen achieved lower BP values compared with ATL-based regimen throughout the study; mean difference SBP/DBP 2.7/1.9 mmHg

Outcomes reduced with $A M+P E R$ vs ATL $+B F Z$ include:

- Nonfatal MI (incl. silent) plus fatal CHD [HR 0.90 (95\% Cl 0.79, 1.02; $P=0.102)]$; primary endpoint

- Nonfatal MI (excl. silent) plus fatal CHD [HR 0.87 (95\% Cl 0.76 $1.0 ; P=0.0458)]$

- Total coronary endpoint [HR $0.87(95 \% \mathrm{Cl} 0.79,0.96 ; P=0.007)]$

- Total CV events and procedures [HR 0.84 (95\% Cl 0.78, 0.90; $P<0.0001)]$

- All-cause mortality [HR $0.76(95 \% \mathrm{Cl} 0.65,0.90 ; P=0.001)]$

- CV mortality [HR $0.76(95 \% \mathrm{Cl} 0.65,0.90 ; P=0.001)]$

- Fatal and nonfatal stroke [HR $0.77(95 \% \mathrm{Cl} 0.66,0.89 ; P=0.0003)]$

10305 patients with

hypertension plus $\geq 3$

other CV risk factors and cholesterol levels $\leq 6.5 \mathrm{mmol} / \mathrm{L}$ (ASCOT-LLA)

\section{RCT including}

$\begin{array}{ll}\text { CAFE } & \text { RCT including } \\ \text { Investigators } & 2199 \text { patients from }\end{array}$

$2006^{\mathrm{c}}$ five ASCOT centers

Deckers

Post-hoc analysis of RCT including 12218 patients with stable CAD
- PER treatment resulted in a risk reduction $[19 \%(95 \% \mathrm{Cl}-7 \%$, $38 \% ; P=0.13)]$ of similar magnitude in the composite primary endpoint to that seen in the main EUROPA population

PER (8 mg/d) vs PLA for 3 y

- Primary endpoint reduced by $53 \%$ compared with placebo in the AML \pm PER plus ATV group, but only by $16 \%$ in the ATL $\pm B F Z+A T V$ group

- Statistically significant interaction between blood pressure lowering and lipid lowering was demonstrated $(P=0.025)$

50-100 mg + BFZ $1.25-2.5 \mathrm{mg})+$ ATV $10 \mathrm{mg}$ or PLA

- Similar reductions in BP for both treatment groups $(-26 /-13.8 \mathrm{mmHg}$ for ATL $\pm \mathrm{THZ} ;-27.8 /-15.7 \mathrm{mmHg}$ for AML \pm PER

AML-based regimen (AML 5-10 mg \pm PER 4-8 mg) or ATL-based regimen (ATL 50-100 mg \pm BFZ $1.25-2.5 \mathrm{mg}$ ) over 4 y

- Significantly lower central aortic systolic pressure and central pulse pressure for AML \pm PER (AUC difference $4.3 \mathrm{mmHg}$ and $3.0 \mathrm{mmHg}$, respectively; $P<0.0001)$

PER (8 mg/d) vs PLA for 3 y Mean follow-up period 4.1 y
- Risk reduction for the composite primary endpoint was consistent for low-, intermediate-, and high-risk patients (HR $0.88,0.68$, and 0.83 , respectively)

aSubstudy of EUROPA 2003; ' bubstudy of PROGRESS 2003a; 'Substudy of ASCOT; dPost-hoc analysis of EUROPA 2003.

AF atrial fibrillation; AML amlodipine; ATL atenolol; ATV, atorvastatin; AUC, area under the curve; BFZ bendroflumethiazide; BP, blood pressure; CAD, coronary artery disease; CHD, coronary heart disease; $\mathrm{CHF}$, congestive heart failure; Cl, confidence interval; CV, cardiovascular; d, day; DBP, diastolic blood pressure; HR, hazard ratio; IND, indapamide; MI, myocardial infarction; PER, perindopril; PLA, placebo; RCT, randomized controlled trial; RRR, relative-risk reduction; SBP, systolic blood pressure; THZ, thiazide; TIA, transient ischemic attack; y, year. 
$(P=0.02)$ and nonfatal $\mathrm{Ml}$ by $38 \%$ (Table 5$)$. This benefit was also seen in a subpopulation of patients with atrial fibrillation where active treatment was associated with a $38 \%$ reduction in major vascular events (Arima et al. 2005). In addition, the reduction in risk of major coronary events was similar in patients with or without hypertension at baseline (PROGRESS 2003a). This demonstrates clear benefits of treatment for high-risk, nonhypertensive individuals as well as for those with hypertension. Among participants treated with combination therapy (perindopril plus indapamide), the risk of any major coronary event was lower than in placebo-treated patients, but the risk was no different for patients receiving perindopril monotherapy compared with placebo. It was concluded that 5 years of treatment with perindopril plus indapamide would have resulted in the avoidance of one major nonfatal vascular event among every 11 patients [95\% confidence interval (Cl) 9, 16] assigned active treatment (PROGRESS 2003a).

There is also evidence that a perindopril-based regimen reduces the risk of CHF developing. Active treatment with the perindoprilbased regimen in the PROGRESS study reduced the risk of $\mathrm{CHF}$ by $26 \%(P=0.02)$ and both hypertensive and nonhypertensive patients benefited equally (27\% risk reduction for both groups) (PROGRESS 2003a). In addition, there was a nonstatistically significant trend towards a greater risk reduction achieved with combination therapy compared with perindopril alone (Table 5).

Recently published results from the large (19 257 patients) ASCOTBPLA have shown a greater benefit of an antihypertensive regimen of CCB plus an ACE inhibitor compared with a beta blocker plus a diuretic for the prevention of adverse cardiovascular outcomes, and less risk of induction of diabetes in hypertensive patients at moderate risk of developing cardiovascular events (Dahlöf et al. 2005) (Table 5). Patients were randomized to either amlodipine 5-10 mg/day adding perindopril 4-8 mg/day as required (amlodipine \pm perindopril regimen, $n=9639$ ), or atenolol 50-100 mg adding bendroflumethiazide $1.25-2.5 \mathrm{mg}$ and potassium as required (atenolol-based regimen, $n=9618$ ). At the end of the trial, most patients (78\%) were taking at least two antihypertensive drugs and only $15 \%$ and $9 \%$ were taking amlodipine and atenolol monotherapy, respectively. Throughout the study a mean of $59 \%$ of patients were taking perindopril ( $9 \%$ alone plus $50 \%$ in combination with another drug) and $70 \%$ of patients were taking atenolol (15\% alone plus $55 \%$ in combination with bendroflumethiazide).

ASCOT-BPLA was terminated early, after 5.5 years of follow-up, on recommendation of the data safety monitoring board because compared with those patients allocated the amlodipine \pm perindopril regimen, those allocated the atenololbased regimen had significantly higher mortality plus worse outcomes on several other endpoints. The likelihood of hypertensive patients having a primary endpoint of nonfatal (including silent) $\mathrm{MI}$ and fatal CHD were 10\% lower (nonsignificant) if they were treated with the amlodipine \pm perindopril regimen compared with the atenolol-based regimen. The study was powered for 1150 patients to have such events, but in fact only 903 occurred by the time of the early termination. Although the study was underpowered for this endpoint, it is likely that it would have reached statistical significance had the study run its course.
Nevertheless, there were statistically significant $(P \leq 0.05)$ reductions in most of the secondary endpoints for patients randomized to the amlodipine \pm perindopril regimen. These included nonfatal (excluding silent) $\mathrm{MI}$ and fatal CHD (13\% reduction), total coronary events (13\%), total cardiovascular events and procedures (16\%), all-cause mortality (11\%), and cardiovascular mortality (24\%). The difference in all-cause mortality was attributable to cardiovascular mortality as noncardiovascular mortality was similar for the two treatments ( 475 and 478 deaths for the amlodipine \pm perindopril regimen and atenolol-based regimen, respectively). Patients allocated to the amlodipine-based regimen were also $30 \%$ less likely to develop diabetes compared with those allocated to atenolol-based treatment ( $P=0.0001)$ (Dahlöf et al. 2005).

Compared with patients randomized to the atenolol-based regimen, blood pressure values were lower throughout the 5.5-year trial in patients allocated the amlodipine \pm perindopril regimen. Although the differences were greatest after 3 months $(5.9 / 2.4 \mathrm{mmHg})$, the average difference was $2.7 / 1.9 \mathrm{mmHg}$ throughout the study. Perhaps surprisingly, a further analysis found no temporal link between the degree of blood pressure reduction and event rates, suggesting that factors other than blood pressure control may produce the benefits observed (Poulter et al. 2005). However, in an accompanying editorial, Staessen and Birkenhäger (2005) criticized this analysis on the grounds of inappropriate exclusion of a number of patients, and strongly suggested that blood pressure lowering was responsible for most of the benefit seen in ASCOT.

Interestingly, a substudy of ASCOT, the Conduit Artery Function Evaluation (CAFE) study, showed no difference in SBP between the two treatment groups (CAFE Investigators 2006). However, central aortic systolic pressure and central aortic pulse pressure were significantly lower with amlodipine \pm perindopril therapy than with atenolol-based therapy. Modeling methods demonstrated a significant relationship of central aortic pulse pressure to a composite endpoint of cardiovascular events or procedures and development of renal impairment $(P<0.0001)$.

The lipid-lowering arm of ASCOT (ASCOT-LLA) added atorvastatin $10 \mathrm{mg}$ or placebo to the amlodipine \pm perindopril or atenolol \pm bendroflumethazide regimens. The study showed that the benefits of atorvastatin were modified by the concomitant antihypertensive regimen (Sever et al. 2005). The primary endpoint was significantly reduced $(53 \%)$ in the amlodipine \pm perindopril plus atorvastatin group versus placebo, but only a nonsignificant reduction of $16 \%$ was achieved in the atenolol \pm bendroflumethazide plus atorvastatin group. Other benefits for atorvastatin versus placebo were also greater in the amlodipine \pm perindopril group than in the atenolol \pm bendroflumethazide group.

In summary, it is established that along with other antihypertensive agents, ACE inhibitors are able to prevent cardiovascular complications in patients with hypertension (Turnbull 2003). Although results from all studies are not completely consistent, and it is of note that the results from ASCOT-BPLA are the subject of considerable debate (Brady 2005; Hird 2005; Messerli \& Sichrovsky 2005; Staessen \& Birkenhäger 2005; Williams 2005), overall, the evidence presented here confirms that perindopril, 
when used alone or as a component of a blood pressure-lowering regimen, is effective in reducing cardiovascular complications in patients with hypertension with or without other risk factors.

\section{Improvement in endothelial dysfunction}

Perindopril was the only drug (of six antihypertensive drugs from different classes) to improve endothelial function from baseline values after 6 months of treatment (Ghiadoni et al. 2003). In this study involving 168 hypertensive patients, all treatments reduced blood pressure to a similar degree, but only perindopril increased flow-mediated dilation of the brachial artery (from $5.1 \pm 2.0 \%$ to $6.4 \pm 2.4 \%, P<0.01)$ compared with normotensive control subjects.

The reduction in cardiovascular events seen in EUROPA was greater than that expected for the observed reduction in blood pressure (mean $5 / 2 \mathrm{mmHg}$ ) achieved with perindopril. It was suggested that blood pressure lowering alone could not be completely responsible for the observed benefits of the drug as the effects were similar in patients with or without hypertension or whose blood pressure remained unchanged during the study. This implies that other consequences of ACE inhibition, such as specific antiatherosclerotic effects (improvement in endothelial function), may also be involved (Fox 2003). However, a substudy of EUROPA [PERindopril Function of the Endothelium in Coronary artery disease Trial (PERFECT)] (Bots et al. 2002) involving 333 patients failed to show a statistically significant drug-related effect on endothelial function (measured as flow-mediated vasodilation) (Bots et al. 2005). Instead a modest long-term improvement from baseline with both perindopril and placebo was seen, with a nonsignificant difference of $0.55 \%$ between the two treatment groups after 3 years (Bots et al. 2005). Reasons as to why the study failed to show a statistically significant effect include heterogeneity in the patient population plus severely diseased endothelium unable to respond to treatment.

It must be considered that perindopril may not necessarily achieve its beneficial effects via the endothelium. However, initial results from another EUROPA subanalysis [(PERindopril, Thrombosis, InflammatioN, Endothelial dysfunction and Neurohormonal activation Trial (PERTINENT)] (Scientific Committee of the PERTINENT substudy, EUROPA-PERTINENT subcommittee 2003) provide indirect evidence that perindopril treatment does improve endothelial function. Plasma markers of endothelial dysfunction (von Willebrand factor and D-dimer) and systemic inflammation [C-reactive protein (CRP) and fibrinogen] were determined in this case-cohort study involving up to 1200 patients (Ceconi et al. 2005). At baseline, marker levels were at the upper range of normal in the study population. After 1 year of treatment with perindopril the markers of endothelial dysfunction, but not systemic inflammation, were significantly reduced compared with placebo $(P<0.05)$. Another measure of endothelial function from the PERTINENT study involved incubating serum from patients $(n=98)$ treated for 1 year with placebo or perindopril with human umbilical vein endothelial cells in culture to mimic the effects of circulating blood on endothelial function (Ferrari 2004).
The results showed that serum from treated patients restored the bradykinin/AT II imbalance and reduced inflammatory marker levels. For example, tumor necrosis factor alfa levels were reduced to $24.6 \mathrm{pg} / \mathrm{mL}$ by serum from perindopril-treated patients compared with $28.9 \mathrm{pg} / \mathrm{mL}(P<0.05)$ with serum from placebotreated patients.

A randomized, double-blind, placebo-controlled study in 18 obese healthy volunteers over 4 weeks did not show any effect of perindopril $4 \mathrm{mg} /$ day on flow-mediated vasodilation of the brachial artery, although it did significantly lower blood pressure compared with placebo (Williams et al. 2006). Obviously, this study was limited by its small sample size and short treatment duration. A further double-blind, randomized study examined carotid distensibility after 7 months of treatment with perindopril 4 or $8 \mathrm{mg}$ in 57 hypertensive patients with type 2 diabetes (Tropeano et al. 2006). Blood pressure decreased in both groups, with no significant difference between doses, but carotid distensibility increased significantly more with perindopril $8 \mathrm{mg}$ than with perindopril $4 \mathrm{mg}$. Similarly, carotid internal diameter and elastic modulus were significantly lower with the higher dose. The results suggest that perindopril reduces carotid stiffness through inward remodeling, leading to a reduction in wall stress and thus reducing elastic modulus. These effects were independent of the level of blood pressure reduction.

Therefore, there is some evidence that perindopril treatment does improve endothelial function in the clinic following demonstrations that ACE inhibitors prevent endothelial dysfunction in experiments in animals and humans (Thuillez et al. 1995; Mancini 2000).

\section{Prevention of cerebrovascular events}

There is evidence that active treatment with a perindopril-based regimen (i.e. perindopril plus indapamide) reduces the likelihood of further strokes in patients who have previously suffered a stroke or a TIA.

In the ASCOT-BPLA study treatment, the amlodipine \pm perindopril regimen reduced the secondary outcome of risk of fatal and nonfatal stroke by $23 \%(P=0.0003)$ compared with the atenololbased regimen (Dahlöf et al. 2005; Table 6).

More direct evidence of the beneficial effect of perindopril on the risk of stroke comes from the large multinational PROGRESS study. One of the several outcomes of this study was to determine the risk of stroke in patients treated with a perindopril-based regimen versus placebo (PROGRESS 2001). After a mean followup of 3.9 years it was found that active treatment significantly reduced the risk of stroke by $28 \%$ when compared with placebo $(P<0.0001)$. This effect was not influenced by patients' gender, although there was some evidence that proportional risk reductions were greater in patients aged under 65 years than in older patients (Rodgers et al. 2004). Recurrent stroke risk was also reduced by $38 \%$ in a subpopulation of patients with diabetes (Berthet et al. 2004), and by $34 \%$ in patients with atrial fibrillation at baseline in this study (Arima et al. 2005). In addition, stroke 
risk was also reduced by $39 \%$ in participants of Asian origin compared with $22 \%$ in Western participants (Rodgers et al. 2004). With this regional difference in mind it is also notable that the risk of pneumonia was significantly reduced by active treatment among patients of Asian ethnicity $(47 \%, P=0.01)$ compared with non-Asians (5\%, $P=0.7)$ (Ohkubo et al. 2004). This finding supports evidence from observational studies that ACE inhibitors (but not other blood pressure-lowering drugs) reduce the risk of pneumonia specifically among Asian populations possibly through downstream effects of ACE polymorphisms (Ohkubo et al. 2004).

PROGRESS also showed that the annual rate of new incidences of stroke in the total population was $2.7 \%$ with active treatment and $3.8 \%$ in the control group (PROGRESS 2001). Compared with placebo treatment, fewer patients in the active treatment group had strokes that were fatal or disabling, and fewer in the active group had severe strokes. In addition, perindopril treatment reduced the risk of either ischemic stroke or cerebral hemorrhage (risk reduction 24 and 50\%, respectively) compared with placebo treatment (Chapman et al. 2004). Among participants treated with the combination of perindopril plus indapamide $(58 \%$ receiving active treatment) stroke risk was reduced by $43 \%$ compared with placebo. In contrast, for patients treated with perindopril alone the risk of stroke was reduced by only $5 \%$ compared with placebo. Therefore, the markedly greater reduction in blood pressure achieved with combination therapy compared with perindopril alone (Table 4) appears to account for this difference in outcome. This was further investigated in a post-hoc analysis evaluating the effect of treatment according to blood pressure levels at baseline, and levels achieved after treatment (Arima et al. 2006). The results suggested that there were greater reductions in risk of stroke with combination therapy than with perindopril alone, regardless of blood pressure level at baseline. In addition, lower blood pressure achieved during follow-up was strongly associated with a lower risk of stroke. These data agree with findings that more intensive blood pressure lowering confers greater reductions in stroke risk (Neal et al. 2000; Turnbull 2003).

Patient outcomes in terms of dementia and cognitive decline were also shown to benefit from active treatment in the PROGRESS study (PROGRESS 2003b). The risk of dementia and cognitive decline were improved by active treatment by $12 \%$ (nonsignificant) and 19\% $(P=0.01)$, respectively. In addition, the risk of the composite outcomes of dementia with recurrent stroke and cognitive decline with recurrent stroke were reduced by $34 \%(P=0.03)$ and $45 \% \quad(P=0.001)$, respectively, following active treatment. It is interesting to note that there was no statistically significant effect of combination treatment compared with single-drug therapy alone on the risk of any of these outcomes. However, it is possible that too few events were recorded in the subgroups to allow definitive conclusions to be drawn (PROGRESS 2003b). Results from PROGRESS in part counter the claims that an excessive fall in blood pressure may actually increase the risk of silent brain infarct (SBI) and dementia (Hasegawa et al. 2004). A substudy involving 667 patients within PROGRESS was specifically designed to determine the risk of $\mathrm{SBI}$ in the active and placebo-treated groups. The data showed that moderate blood pressure lowering with the perindopril-based regimen did not increase the risk of SBI and brain atrophy in patients with a history of stroke (Table 6). Furthermore, reducing DBP may actually decrease the risk of SBI irrespective of the type of index stroke (i.e. the most recent stroke at the time of randomization) (Hasegawa et al. 2004). A smaller PROGRESS substudy also showed that active treatment stopped or delayed the progression of cerebral white matter hyperintensities (WMH) in patients with stroke (Dufouil et al. 2005). WMH are often seen in magnetic resonance images (MRI) from elderly patients or those with stroke, and are associated with a number of outcomes including cognitive impairment or dementia. Active treatment reduced the risk of new WMH by $43 \% \quad(P=0.17)$ compared with placebo in patients with an $\mathrm{MRI}$ at baseline and mean follow-up of 36 months. The mean volume of new WMH was also decreased significantly with active treatment compared with placebo, the difference being greatest for patients with severe $\mathrm{WMH}$ at entry.

Active treatment also reduced the odds of disability by $24 \%$ $(P<0.001)$ and dependency ("requirement of regular help with everyday activities") by $16 \%(P=0.04)$ in the PROGRESS trial (PROGRESS 2003c). Thus, the effects of active treatment appeared to be mediated primarily through the prevention of disability and dependency associated with recurrent stroke. Four years of treatment with the perindopril-based regimen would be expected to result in the avoidance of one case of long-term disability for every $30(95 \% \mathrm{Cl} 19,79)$ patients (PROGRESS 2003c). There was no statistically significant difference between combination therapy and perindopril alone for the prevention of either disability or dependence.

In summary, perindopril-based treatment is effective in the secondary prevention of stroke and associated disability and dependence. There is also substantial evidence that cerebrovascular outcomes including dementia and cognitive decline can be attenuated with perindopril-based therapy.

\section{Tolerability}

There is good evidence that perindopril is a well-tolerated antihypertensive therapy. In common with other ACE inhibitors, the most frequent adverse events seen with perindopril are dry cough and gastrointestinal (Gl) symptoms. These are typically mild and reversible on treatment cessation.

In a 12-month postmarketing survey involving 42245 evaluable patients (92\% of the original cohort) treated with perindopril 2-8 mg/day for 12 months, the most common spontaneously reported clinical event was cough, in 9.6\% (Speirs et al. 1998). Other commonly described events were dyspepsia/GI upset (1.9\%), asthenia (1.8\%), headache (1.4\%), and dizziness/vertigo (1.3\%). Withdrawals due to suspected adverse reactions were reported in 2369 patients (total incidence 5\%; 3.2\% male and $6.1 \%$ female patients). Fourteen serious adverse events were reported, including three cases of angiogenic edema, and 11 serious allergic reactions. 


\section{Table 6 | Effect of perindopril in preventing cerebrovascular events}

\begin{tabular}{|llll} 
Level of evidence & Reference & Design & Treatment and mean dose \\
\hline 2 & PROGRESS & RCT including & PER (4 mg/d, all patients) plus \\
& 2001 & $\begin{array}{l}6105 \text { patients with } \\
\text { prior stroke or TIA }\end{array}$ & IND (2-2.5 mg/d, 58\% patients) \\
& & & Mean follow-up 3.9 y
\end{tabular}

Rodgers

et al. 2004

Ohkubo

et al. 2004

Chapman

et al. 2004

PROGRESS

$2003^{b}$

Mean follow-up 3.9 y

PROGRESS

$2003^{c}$

$\begin{array}{ll}\text { Berthet } & \text { RCT including } \\ \text { et al. 2004 } & \begin{array}{l}\text { 761 patients } \\ \text { with diabetes }\end{array}\end{array}$

PER $(4 \mathrm{mg} / \mathrm{d}) \pm$ IND $(2-2.5 \mathrm{mg} / \mathrm{d})$ vs PLA with diabetes

Mean follow-up 3.9 y

\section{Outcomes}

- RRR for stroke $28 \%(95 \% \mathrm{Cl} 17 \%, 38 \% ; P<0.0001)$ with active treatment vs PLA

- Annual incidence of new stroke $3.8 \%$ with PLA vs $2.7 \%$ with active treatment

- RRR for fatal or disabling stroke $33 \%$ (95\% Cl 15\%, 46\%) with active treatment vs PLA

- Combination therapy reduced stroke risk by $43 \%$ (95\% Cl $30 \%$, $54 \%)$. PER alone reduced stroke risk by $5 \%(95 \% \mathrm{Cl}-19 \%, 23 \%)$

- Risk of stroke reduced in both hypertensive and nonhypertensive patients

- Proportional risk reductions in stroke somewhat greater in patients aged $<65$ y compared with those $\geq 65$ y

- Risk of stroke reduced by $39 \%$ in Asian patients compared with $22 \%$ in Western patients

- Risk of pneumonia reduced by $47 \%$ in Asian patients compared with $5 \%$ in non-Asian patients

- Reduced risk of recurrent stroke irrespective of the stroke subtype: RRR all IS $24 \%$ (95\% Cl 10\%, 35\%); ICH 50\% (95\% Cl 26\%, 67\%); unknown type $18 \%(95 \% \mathrm{Cl}-24 \%, 45 \%)$

RRRs for active treatment vs PLA:

- Dementia $12 \%(95 \% \mathrm{Cl}-8 \%, 28 \% ; P=0.2)$

- Cognitive decline 19\% (95\% Cl 4\%, 32\%; $P=0.01)$

- Dementia with recurrent stroke 34\% (95\% Cl 3\%, 55\%; $P=0.03)$

- Cognitive decline with recurrent stroke $45 \%$ (95\% Cl $21 \%$, $61 \% ; P<0.001)$

- Active treatment reduced the odds of disability and dependency by $24 \%$ (OR $0.76 ; 95 \% \mathrm{Cl} 0.65,0.89 ; P<0.001)$ and $16 \%$ (OR $0.84 ; 95 \% \mathrm{Cl} 0.71,0.99 ; P<0.04$ ), respectively

- NS difference between odds of disability or dependency with combination therapy or PER alone

- Proportional risk reduction in stroke 38\% (95\% Cl 8\%, 58\%) with active treatment vs PLA

- Absolute risk reduction for recurrent stroke in diabetic patients was equivalent to one stroke avoided among every $16(95 \% \mathrm{Cl} 9,111)$ patients treated for $5 \mathrm{y}$

Hasegawa et RCT including al. 2004a 667 patients with

PER (4 mg/d) \pm IND (2 mg/d) prior stroke or TIA

Mean follow-up $3.9 \mathrm{y}$

- No difference in new SBI detected in PLA treated vs active treated group (15 vs $12.5 \%$, respectively; $P=0.34$ )

- BP lowering with PER-based regimen did not increase risk of $\mathrm{SBI}$ and brain atrophy in patients with stroke history. Reducing DBP may decrease the risk of SBI

\section{Arima et al. RCT including}

$2005^{a} \quad 476$ patients with

prior stroke or TIA

and $\mathrm{AF}$ at baseline

PER (4 mg/d, all patients) plus IND (2-2.5 mg/d, 58\% patients)

- In patients with $\mathrm{AF}$, active treatment reduced stroke by $34 \%(95 \% \mathrm{Cl}-13 \%, 61 \%)$ vs PLA treatment

vs PLA

Mean follow-up 3.9 y

$\begin{array}{ll}\text { Dahlöf et al. } & \text { RCT including } \\ 19257 \text { patients }\end{array}$

19257 patients

with hypertension

plus $\geq 3$ other $\mathrm{CV}$

risk factors

(ASCOT-BPLA)

Dufouil et al. RCT including

$2005^{a} \quad 192$ patients with

prior stroke or TIA

AML-based regimen

(AML 5-10 mg \pm PER 4-8 mg)

or ATL-based regimen (ATL

$50-100 \mathrm{mg} \pm \mathrm{BFZ}$

$1.25-2.5 \mathrm{mg}$ )

$\operatorname{PER}(4 \mathrm{mg} / \mathrm{d}) \pm \operatorname{IND}(2 \mathrm{mg} / \mathrm{d})$

vs PLA

Mean follow-up 3 y

- HR for AML- vs ATL-based regimen, fatal and nonfatal stroke 0.77 (95\% Cl 0.66, 0.89; $P=0.0003)$

- More WMH developed in PLA vs active treated group (16 vs $9 \%, P=0.17$ )

- Volume of WMH was larger in PLA vs active treated group $\left(2.0 \pm 0.7 \mathrm{~mm}^{3}\right.$ vs $\left.1.8+0.5 \mathrm{~mm}^{3}, P=0.012\right)$. The treatment effect on the total volume of new WMH was particularly marked in patients with severe WMH at baseline $(P<0.0001)$

$\begin{array}{ll}\text { Arima et al. } & \text { Post-hoc analysis } \\ 2006^{b} & \text { of RCT including } \\ & 6105 \text { patients with } \\ & \text { prior stroke or TIA }\end{array}$

PER $(4 \mathrm{mg} / \mathrm{d}) \pm \operatorname{IND}(2-2.5 \mathrm{mg} / \mathrm{d})$ vs PLA

Mean follow-up 3.9 y

- Similar reductions in risk of stroke in four subgroups defined by baseline SBP $(<120,120-139,140-159, \geq 160 \mathrm{mmHg})$

- Reduction in risk of stroke consistently higher with combination therapy than with PER alone, regardless of baseline SBP

- Lowest risk of stroke in subgroup with lowest follow-up SBP levels; risks rose progressively with higher SBP levels

aSubstudy of PROGRESS 2001; b Post-hoc analysis of PROGRESS 2001

$\mathrm{AF}$, atrial fibrillation; $\mathrm{AML}$, amlodipine; $\mathrm{ATL}$, atenolol; BFZ, bendroflumethiazide; $\mathrm{BP}$, blood pressure; $\mathrm{Cl}$, confidence interval; $\mathrm{CV}$, cardiovascular; d, day; DBP, diastolic blood pressure; $\mathrm{HR}$, hazard ratio; ICH, intracerebral hemorrhage; IND, indapamide; IS, ischemic stroke; NS, not significant; OR, odds ratio; PER, perindopril; PLA, placebo; RCT, randomized controlled trial; RRR, relativerisk reduction; $\mathrm{SBI}$, silent brain infarct; $\mathrm{SBP}$, systolic blood pressure; TIA, transient ischemic attack; WMH, white matter hyperintensities; y, year. 
Perindopril $8 \mathrm{mg} /$ day was shown to be well tolerated in the EUROPA study, which involved over 12000 patients with CAD. After 3 years, $81 \%$ of patients assigned to perindopril compared with $84 \%$ assigned to placebo were still taking study medication. Most patients who were assigned to perindopril continued on the $8 \mathrm{mg}$ dose; only $7 \%$ had reduced to the $4 \mathrm{mg}$ dose at 3 years. After randomization, withdrawals from treatment were similar to those for placebo; cough was a reason for withdrawals in $2.7 \%$ of perindopril-treated patients compared with $0.5 \%$ treated with placebo (Fox 2003).

Perindopril-based treatment was also shown to be well tolerated in the PROGRESS study in 6105 patients with a history of previous stroke or TIA (PROGRESS 2001). Therapy was continued in $86 \%$ of those assigned active treatment compared with $87 \%$ assigned placebo. Premature discontinuation was similar between the two groups (active $23 \%$ vs placebo $21 \%)$. The main reasons for discontinuation were participant's decision (7.6 vs $8.2 \%$ ), cough (2.2 vs $0.4 \%$ ), and hypotension (2.1 vs $0.9 \%)$.

\section{Economic evidence}

There is some evidence regarding the cost effectiveness of perindopril in the prevention of CVD based on data from the EUROPA study.

In one report the medical costs for CVD per patient were estimated and cost per life-year gained per patient in the Netherlands, France, Italy, and Poland was determined (Niessen et al. 2005). The results showed that the life-years gained per patient ranged from 0.182 to 0.209 per patient lifetime in the four countries and that the change in medical costs also ranged from $€ 462$ to $€ 1861$ per patient. Thus the incremental costeffectiveness ratio (ICER) ranged from €2536 (in Poland) to €8904 (in Italy) per life-year gained. The probability that the ICER for a given country falls below a threshold value of $€ 20000$ varied from 73 to $92 \%$ and from 80 to $94 \%$ at a threshold of $€ 30000$. Therefore, the conclusion from the study was that given prevailing ICER thresholds, perindopril is very likely to be cost effective.

Data from the EUROPA study was also used to assess the cost effectiveness of perindopril $8 \mathrm{mg}$ in patients with stable CAD in the UK (Briggs et al. 2006). The median incremental cost per quality-adjusted life-year (QALY) across the heterogeneous study population was estimated as $£ 9500$ (25th and 75th percentiles $£ 6500$ and $£ 14400$, respectively). Overall, 89\% of the EUROPA population had an incremental cost per QALY below $£ 20000$ and 97\% below £30 000 .

\section{Resource utilization}

One of the most important aspects of successful control of hypertension is adherence to evidence-based therapeutic guidelines. Adherence can lead to more effective control of blood pressure and also has economic implications. In fact, there is recent evidence that considerable cost savings can be achieved if prescribing guidelines are followed. For example, a study conducted in the USA analyzed actual versus potential regimens for 133624 elderly patients with hypertension in a large state pharmaceutical assistance program (Fischer \& Avorn 2004). In keeping with the JNC-7 guidelines, thiazide diuretics were considered to be appropriate first-line therapy for hypertensive patients without specific contraindications, with ACE inhibitors being considered appropriate for hypertensive patients with $\mathrm{CHF}$ or diabetes and nephropathy. The authors identified that $40 \%$ of all prescriptions could be substituted for a more appropriate (i.e. guideline-recommended) regimen. Such substitution would have resulted in potential savings of \$US87.14 per person or \$US11.6 million per year for the program. Extrapolating these results to the national level for this population would lead to savings of $\$$ US1.2 billion per year in the USA. In addition to these savings in drug acquisition, adherence to guideline recommendations should also result in effective blood pressure control and consequent reduction in the risk of costly complications.

Although there is limited information on the cost effectiveness of perindopril monotherapy or in combination, the fact that perindopril (plus other antihypertensive agents) effectively reduces blood pressure, one of a number of proven modifiable factors for CVD, suggests that the burden of CVD would be reduced with effective blood pressure management. The evidence shows that perindopril-based therapies reduce cardiovascular and cerebrovascular outcomes and that the prevention of these outcomes will reduce resource necessary for their treatment. This will vary with the severity of the outcome, and may range from additional drug therapy to costly emergency room treatment and lengthy hospitalization. For example, there is clear evidence that perindopril-based treatment reduces the risk of stroke. Thus, reduction in the numbers of stroke patients requiring intensive treatment, nursing or home help will have a beneficial impact on use of limited resources. Similarly, reductions in the risk of cognitive decline and dementia will also have an impact on the burden on individuals and services managing these conditions.

\section{Patient group/population}

Treatment guidelines identify patients with blood pressure $\geq 140 / 90 \mathrm{mmHg}$ (lower for patients with diabetes) as being appropriate for antihypertensive therapy and/or reassessment on a regular basis (Table 2). As has been reviewed in the Clinical evidence section, perindopril (monotherapy and in combination with indapamide) is effective in controlling hypertension in a variety of patient groups, including those with type 2 diabetes, dyslipidemia, isolated systolic hypertension, peripheral arterial occlusive disease, and the elderly. In addition, beneficial blood pressure control was seen in population of African-Americans with hypertension (Cohn et al. 2004).

In the EUROPA study, all patients (mean age 60 \pm 9 years) had $\mathrm{CHD}, 27 \%$ had hypertension, and $12 \%$ were diabetic. In this large population, perindopril reduced the outcomes of cardiovascular death, MI, cardiac arrest, acute coronary symptoms, and the development of heart failure compared with placebo treatment (Fox 2003). Similarly, the PROGRESS study included 6105 randomized patients (mean age at study 
entry 64 years) with $84 \%$ having an entry diagnosis of stroke, and the remainder an entry diagnosis of TIA alone. Nearly half (48\%) had hypertension and $12 \%$ had diabetes. Among this diverse population of patients with a history of cerebrovascular events, the perindopril-based blood pressure-lowering regimen reduced the risk of stroke and other related outcomes compared with placebo (PROGRESS 2001). This protective effect was also seen in the specific populations with diabetes, and atrial fibrillation at baseline.

The results from ASCOT-BPLA showed that the combination of thiazide and beta blockers was inferior to the ACE inhibitor and CCB combination for the total population and every subgroup (Dahlöf et al. 2005). These findings support the current British Hypertension Society (BHS) guidelines in the use of the $A B / C D$ treatment algorithm. The theory behind the algorithm is that hypertension can be classified as "high" or "low" renin and is best treated with drugs that inhibit [ACE inhibitors/ARBs (A), or beta blockers (B)] or have no effect [CCBs (C) or diuretics (D)] on the renin-angiotensin system (Brown et al. 2003). A or B drugs are more effective in blood pressure lowering in younger Caucasian patients. In contrast, $\mathrm{C}$ or D drugs are less effective at initial blood pressure lowering in these patients and are more suitable in older Caucasians and black patients of any age (Williams et al. 2004).

Patients in ASCOT-BPLA were randomized to initial treatment with either a CCB or beta blocker which was then augmented with an ACE inhibitor or a thiazide diuretic in the respective arms. However, in the clinic, according to the BHS guidelines a typical participant in ASCOT-BPLA would be initiated on C (CCB) or $D$ (thiazide diuretic) as initial therapy to give better initial control of blood pressure and would have advised against initial treatment with a beta blocker or ACE inhibitor (Williams 2005). Yet the additional therapies would be considered appropriate, if not common, using the algorithm and have also been advocated in the ESH/ESC guidelines (ESH/ESC 2003). On the other hand, the combination of a beta blocker and a thiazide diuretic is not generally recommended due to the increased risk of developing type 2 diabetes (Williams et al. 2004). Indeed, results from ASCOT-BPLA confirmed this as patients on the atenolol-based regimen were $30 \%$ more likely to develop diabetes (Dahlöf et al. 2005).

Therefore, the beneficial effect of perindopril has been shown in a number of diverse populations that are representative of patients with hypertension and other cardiovascular risk factors who are likely to be encountered in the clinical environment.

\section{Dosage, administration, and formulations}

In the USA, perindopril is indicated for the treatment of essential hypertension and in patients with stable CAD to reduce the risk of cardiovascular mortality or nonfatal MI. It is available as 2,4 , or $8 \mathrm{mg}$ tablets which should be taken in the morning before food.

For the treatment of hypertension the recommended starting dose is $4 \mathrm{mg}$ once daily and may be titrated to a maximum of
$8 \mathrm{mg}$ once daily to gain optimum blood pressure control. Elderly patients and those with a strongly activated renin-angiotensinaldosterone system should be started on $2 \mathrm{mg}$ once daily. Patients already receiving diuretics should have this treatment stopped 2-3 days before starting perindopril $2 \mathrm{mg}$. If required, diuretics may be reinstated later at a lower dose. Coversyl Plus ${ }^{\circledR}$ (tablets containing perindopril $4 \mathrm{mg}$ and indapamide $1.25 \mathrm{mg}$ ) is indicated for patients in whom essential hypertension is not adequately controlled by perindopril alone. However, this preparation is not available in the USA.

For the treatment of symptomatic heart failure the starting dose of perindopril is $2 \mathrm{mg}$, which may be increased to $4 \mathrm{mg}$ if well tolerated, and is generally combined with a nonpotassium sparing diuretic and/or digoxin and/or a beta blocker under close supervision.

As with other ACE inhibitors, blood pressure, renal function, and serum potassium should be monitored. In patients with impaired renal function the dosage should be based on creatinine clearance. When pregnancy is detected perindopril treatment should be discontinued as soon as possible. In addition, perindopril is also contraindicated in patients with a history of angioedema related to previous treatment with an ACE inhibitor. Perindopril is not recommended in children.

\section{Clinical value}

The clinical evidence for perindopril covers both patient- and disease-oriented outcomes as shown in the summary table at the beginning of this review.

There is clear evidence that perindopril, alone or in combination with indapamide, achieves clinically significant reductions in SBP and DBP. In addition, there is evidence from one large, community-based, open-label study that blood pressure control was achieved in almost half of all hypertensive patients within 12 weeks of starting treatment (Julius et al. 2004). The benefit from reducing blood pressure with an antihypertensive agent is the reduction in risk of the serious complications that may arise from this condition (Turnbull 2003). Most evidence regarding the reduction in morbidity and mortality associated with perindopril has been obtained from the large EUROPA, PROGRESS, and ASCOT-BPLA studies which considered patient-oriented outcomes in parallel with changes to blood pressure. Perindopril treatment reduced cardiovascular mortality, MI, risk of $\mathrm{CHF}$, and cardiac arrest by $20 \%$ in patients with CAD irrespective of their level of risk. The magnitude of this benefit was greater than that predicted by the observed reduction in blood pressure in this study. Investigations into this effect show that there is some evidence supporting additional antiatherosclerotic effects and improvements in endothelial function with perindopril.

Evidence for beneficial effects of perindopril-based treatment on cerebrovascular outcomes has come from the PROGRESS study which has demonstrated significant reductions in the risk of stroke. The greatest benefit was seen when blood pressure was lowered more effectively by the combination of perindopril and indapamide 
compared with perindopril alone. PROGRESS substudies also demonstrated that the risk of dementia, cognitive decline, and disability were reduced by active treatment in this population.

In the ASCOT-BPLA study, perindopril was used as an additional therapy available to patients treated initially with the CCB amlodipine. This study provided evidence that the better blood pressure control achieved with the amlodipine \pm perindopril regimen therapy compared with atenolol-based treatment was most likely responsible for the reduction in stroke, cardiovascular events, and all-cause mortality. It is also possible that other properties of perindopril including improvement in endothelial function may have contributed to these clinical outcomes as well. ASCOT-BPLA also confirmed that patients given the combination of a beta blocker and thiazide diuretic are more likely to develop diabetes compared with the combination of the newer classes of antihypertensive agents.

The question arises as to whether all the beneficial effects and outcomes seen with perindopril in these large clinical studies are drug specific, or are part of a class effect. The antihypertensive effects of ACE inhibitors are well established as is their beneficial effect on patients at high risk of CVD (Turnbull 2003). Nevertheless, it remains to be confirmed whether the specific morbidity and mortality-related outcomes from the EUROPA, PROGRESS, and ASCOT-BPLA trials are specific for perindopril or may in part be shared with other ACE inhibitors. In particular, the greater reduction in cardiovascular events achieved with perindopril were greater than the observed reduction in blood pressure suggested, implying other drug-related effects.

The question as to whether these effects are drug or class specific cannot be answered definitively until similar clinical studies are carried out with comparative drugs. However, the likelihood of this occurring is remote mainly because of issues of cost and motivation. Certainly there are physicochemical and pharmacologic properties of perindopril that are not shared by other ACE inhibitors and may account for its efficacy (Table 3). For example, it is likely that antiatherosclerotic effects depend on perindopril's affinity for tissue ACE in the endothelium and lipophilicity allowing penetration of atherosclerotic plaques. Until directly comparative trials with other ACE inhibitors are conducted, in adherence to published guidelines regarding class effects it is sensible to use only the clinically proven ACE inhibitor when choosing an agent to improve the required outcome (e.g. risk reduction in cardiovascular event, stroke) (McAlister et al. 1999). Given that there is a large body of evidence clearly showing the benefits for perindopril-based treatment on these outcomes then it would be prudent to use the proven perindoprilbased drug regimen to achieve them in the clinic.

Economic evidence for perindopril has been limited to costeffectiveness analyses from the EUROPA study. Reducing the risk of cardiovascular events, other morbidities, and mortality is likely to have a beneficial economic outcome despite perindopril's high acquisition cost compared with other ACE inhibitors (on a mg-to-mg basis) (Stoysich \& Massoomi 2002). Whether perindopril $8 \mathrm{mg}$ can be considered to be cost effective depends upon individual healthcare systems' threshold values for cost effectiveness. The data from EUROPA showed that for most patients the incremental cost per QALY gained was lower than threshold values of $€ 20000$ in Europe or $£ 20000$ in the UK. Economic analyses from other perindopril studies are awaited with interest.

In summary, there is a large volume of good quality evidence supporting the use of perindopril in the control of hypertension and avoidance of associated complications. Although perindopril alone may be used to reduce blood pressure, the fact that most patients require two or more drugs to achieve current blood pressure goals means that most monotherapy for hypertension is usually inadequate (Williams et al. 2004). Recent evidence has indicated that perindopril-based treatment is likely to have an increasing role in the management of patients with hypertension, stable CAD, or those at risk from further adverse cardiovascular and cerebrovascular events. Further economic analyses are needed to confirm its clinical value, particularly with respect to other ACE inhibitors. Currently the evidence suggests that perindopril is an effective intervention for reducing the burden of CVD.

\section{References}

Anon. The sixth report of the Joint National Committee on Prevention, Detection, Evaluation, and Treatment of high blood pressure. Arch Intern Med. 1997;157:2413-2446.

Arima H, Hart RG, Colman S, et al. Perindopril-based blood pressure-lowering reduces major vascular events in patients with atrial fibrillation and prior stroke or transient ischemic attack. Stroke. 2005;36:2164-2169.

Arima $\mathrm{H}$, Chalmers J, Woodward $\mathrm{M}$, et al. Lower target blood pressures are safe and effective for the prevention of recurrent stroke: the PROGRESS trial. J Hypertens. 2006;24:1201-1208.

Asmar RG, London GM, O'Rourke ME, et al. Amelioration of arterial properties with a perindopril-indapamide very-low-dose combination. $J$ Hypertens. 2001;19(Suppl. 4):S15-S20.

Berthet K, Neal BC, Chalmers JP, et al. Reductions in the risks of recurrent stroke in patients with and without diabetes: the PROGRESS Trial. Blood Press. 2004;13:7-13.

Bots ML, Remme WJ, Lüscher TF, et al. PERindopril - Function of the Endothelium in Coronary artery disease Trial: the PERFECT study - sub study of EUROPA: rationale and design. Cardiovasc Drugs Ther. 2002;16:227-236.

Bots M, Remme W, Luscher T, et al. ACE inhibition and endothelial function: the PERFECT study, substudy of the EUROPA trial: main findings. $J$ Hypertens. 2005;23(Suppl. 2):S21. Abstract 3B.4.

Brady AJB. Big win at ASCOT - amlodipine/peridopril by several lengths over atenolol/bendroflumethiazide. Br J Cardiol. 2005;12:92-93.

Briggs A, Mihaylova B, Sculpher M, et al. The cost-effectiveness of perindopril in reducing cardiovascualr events in patients with stable coronary artery disease using data from the EUROPA study. 55th Annual Scientific Session of the American College of Cardiology; March 11-14, 2006; Atlanta, GA.

Brown MJ, Cruickshank JK, Dominiczak AF, et al. Better blood pressure control: how to combine drugs. J Hum Hypertens. 2003;17:81-86.

CAFE Investigators. Differential impact of blood pressure-lowering drugs on central aortic pressure and clinical outcomes: principal results of the conduit artery function evaluation (CAFE) study. Circulation. 2006;113:1213-1225.

Ceconi C, Fox KM, Remme WJ, et al. Effect of perindopril in patients with stable coronary artery disease: results of inflammatory and thrombosis markers of the PERTINENT study. Eur Heart J. 2005:26(Suppl.). Abstract 3665.

Chapman N, Huxley R, Anderson C, et al. Effects of a perindopril-based blood pressure-lowering regimen on the risk of recurrent stroke according to stroke subtype and medical history; the PROGRESS trial. Stroke. 2004;35:116-121. 
Chobanian AV, Bakris GL, Black HR, et al. The seventh report of the Joint National Committee on Prevention, Detection, Evaluation, and Treatment of high blood pressure: the JNC 7 report. JAMA. 2003;289:2560-2572.

Cohn JN, Julius S, Neutel J, et al. Clinical experience with perindopril in African-American hypertensive patients: a large United States community trial. Am J Hypertens. 2004;17:134-138.

Dahlöf B, Sever PS, Poulter NR, et al. Prevention of cardiovascular events with an antihypertensive regimen of amlodipine adding perindopril as required versus atenolol adding bendroflumethiazide as required, in the Anglo-Scandinavian Cardiac Outcomes Trial-Blood Pressure Lowering Arm (ASCOT-BPLA): a multicentre randomised controlled trial. Lancet. 2005;366:895-906.

Daly CA, Fox KM, Remme WJ, et al. The effect of perindopril on cardiovascular morbidity and mortality in patients with diabetes in the EUROPA study: results from the PERSUADE substudy. Eur Heart J. 2005;26:1369-1378.

Deckers JW, Goedhart DM, Boersma E, et al. Treatment benefit by perindopril in patients with stable coronary artery disease at different levels of risk. Eur Heart J. 2006;27:796-801.

de Leeuw PW. Very-low-dose combination of perindopril and indapamide as novel strategy in first-line management of hypertension. J Hypertens. 2001;19(Suppl. 3):S41-S45.

Dufouil C, Chalmers J, Coskun O, et al. Effects of blood pressure lowering on cerebral white matter hyperintensities in patients with stroke: the PROGRESS (Perindopril pROtection aGainst REcurrent Stroke Study) Magnetic Resonance Imaging Substudy. Circulation. 2005;112:1644-1650.

Dzau VJ, Bernstein K, Celermajer D, et al. The relevance of tissue angiotensinconverting enzyme: manifestations in mechanistic and endpoint data. Am J Cardiol. 2001;88(Suppl.):1L-20L.

ESH/ESC (European Society of Hypertension-European Society of Cardiology) Guidelines Committee. 2003 European Society of Hypertension-European Society of Cardiology guidelines for the management of arterial hypertension. J Hypertens. 2003;21:1011-1053.

Fox KM; EUROPA (EURopean trial On reduction of cardiac events with Perindopril in stable coronary Artery disease) Investigators. Efficacy of perindopril in reduction of cardiovascular events among patients with stable coronary artery disease: randomised, double-blind placebo-controlled, multicentre trial (the EUROPA study). Lancet. 2003;362:782-788.

Ezzati M, Lopez AD, Rodgers A, et al. Selected major risk factors and global and regional burden of disease. Lancet. 2002;360:1347-1360.

Ferrari R. PERTINENT, PERindopril, Thrombosis, InflammatioN, Endothelial dysfunction and Neurohormonal activation Trial, a sub-analysis of EUROPA. European Society of Cardiology congress; August 28-September 1, 2004; Munich, Germany. Results available at: http://www.europatrial.org/pro/pertinent/data_sheet.asp (accessed October 27, 2005).

Fischer MA, Avorn J. Economic implications of evidence-based prescribing for hypertension: can better care cost less? JAMA. 2004;291:1850-1856.

Ghiadoni L, Magagna A, Versari D, et al. Different effect of antihypertensive drugs on conduit artery endothelial function. Hypertension. 2003;41:1281-1286. Guo W, Turlapaty P, Shen Y, et al. Clinical experience with perindopril in patients nonresponsive to previous antihypertensive therapy: a large US community trial. Am J Ther. 2004;11:199-205.

Hansson L, Zanchetti A, Carruthers SG, et al. Effects of intensive bloodpressure lowering and low-dose aspirin in patients with hypertension: principal results of the Hypertension Optimal Treatment (HOT) randomised trial. Lancet. 1998;351:1755-1762.

Hasegawa Y, Yamaguchi T, Omae T, et al. Effects of perindopril-based blood pressure lowering and of patient characteristics on the progression of silent brain infarct: the Perindopril pROtection aGainst REcurrent Stroke Study (PROGRESS) CT Substudy in Japan. Hypertens Res. 2004;27:147-156. Hird M. Was ASCOT won on fact, or publicity? Pharm J. 2005;275:406. Hurst M, Jarvis B. Perindopril: an updated review of its use in hypertension. Drugs. 2001;61:867-896.

Julius S, Cohn JN, Neutel J, et al. Antihypertensive utility of perindopril in a large, general practice-based clinical trial. J Clin Hypertens. 2004;6:10-17.

Kang S, Wu YF, An N, Ren M. A systematic review and meta-analysis of the efficacy and safety of a fixed, low-dose perindopril-indapamide combination as first-line treatment of hypertension. Clin Ther. 2004;26:257-270.
Kearney PM, Whelton M, Reynolds K, et al. Global burden of hypertension: analysis of worldwide data. Lancet. 2005;365:217-223.

Lerebours G, Antony I. Clinical review of perindopril in the treatment of hypertension. Can J Cardiol. 1994;10(Suppl. D):3D-7D.

Lewington S, Clarke R, Qizilbash N, et al. Age-specific relevance of usual blood pressure to vascular mortality: a meta-analysis of individual data for one million adults in 61 prospective studies. Lancet. 2002;360:1903-1913.

McAlister FA, Laupacis A, Wells GA, Sackett DL. Users' guides to the medical literature: XIX. Applying clinical trial results B. Guidelines for determining whether a drug is exerting (more than) a class effect. JAMA. 1999;282:1371-1377.

Mancini GB. Long-term use of angiotensin-converting enzyme inhibitors to modify endothelial dysfunction: a review of clinical investigations. Clin Invest Med. 2000;23:144-161.

Messerli FH, Sichrovsky T. When premature is not premature - the ASCOT study. Eur Heart J. 2005;26:1822-1823.

Mourad JJ, Waeber B, Zannad F, et al. Comparison of different therapeutic strategies in hypertension: a low-dose combination of perindopril/indapamide versus a sequential monotherapy or a stepped-care approach. $J$ Hypertens. 2004;22:2379-2386.

NICE (National Institute for Health and Clinical Excellence). Hypertension: management of hypertension in adults in primary care. Clinical guideline 34 . London: NICE; June 2006. Available at:

http://www.nice.org.uk/guidance/CG34/niceguidance/pdf/English (accessed September 22, 2006).

Neal B, MacMahon S, Chapman N; Blood Pressure Lowering Treatment Trialists' Collaboration. Effects of ACE inhibitors, calcium antagonists, and other blood-pressure-lowering drugs: results of prospectively designed overviews of randomized trials. Lancet. 2000;356:1955-1964.

Neutel JM, Weber MA, Julius S, et al. Clinical experience with perindopril in elderly hypertensive patients: a subgroup analysis of a large community trial. Am J Cardiovasc Drugs. 2004;4:335-341.

Niessen LW, Redekop WK, Deckers JW, et al. Cost-effectiveness of perindopril compared to placebo to prevent cardiovascular events in stable coronary heart disease. Eur Heart J. 2005:26(Suppl.). Abstract 2297.

Ohkubo T, Chapman N, Neal B, et al. Effects of an angiotensin-converting enzyme inhibitor-based regimen on pneumonia risk. Am J Respir Crit Care Med. 2004;169:1041-1045.

Oparil S. Efficacy of perindopril in the treatment of systemic hypertension. Am J Cardiol. 2001;88(Suppl.):3i-12i.

Padwal R, Straus SE, McAlister FA. Cardiovascular risk factors and their effects on the decision to treat hypertension: evidence based review. BMJ. 2001;322:977-980.

Poulter NR, Wedel H, Dahlöf B, et al. Role of blood pressure and other variables in the differential cardiovascular event rates noted in the AngloScandinavian Cardiac Outcomes Trial-Blood Pressure Lowering Arm (ASCOT-BPLA). Lancet. 2005;366:907-913.

PROGRESS Collaborative Group. Randomised trial of a perindopril-based blood-pressure-lowering regimen among 6105 individuals with previous stroke or transient ischaemic attack. Lancet. 2001;358:1033-1041.

PROGRESS Collaborative Group. Effects of a perindopril-based blood pressure-lowering regimen on cardiac outcomes among patients with cerebrovascular disease. Eur Heart J. 2003a;24:475-484.

PROGRESS Collaborative Group. Effects of blood pressure lowering with perindopril and indapamide therapy on dementia and cognitive decline in patients with cerebrovascular disease. Arch Intern Med. 2003b;163:1069-1075.

PROGRESS Collaborative Group. Effects of a perindopril-based blood pressure-lowering regimen on disability and dependency in 6105 patients with cerebrovascular disease. Stroke. 2003c;34:2333-2338.

Rodgers A, Chapman N, Woodward M, et al. Perindopril-based blood pressure lowering in individuals with cerebrovascular disease: consistency of benefits by age, sex and region. J Hypertens. 2004;22:653-659.

Scientific Committee of the PERTINENT substudy, EUROPA-PERTINENT Investigators. PERTINENT - perindopril thrombosis, inflammation, endothelial dysfunction and neurohormonal activation trial: a sub-study of the EUROPA study. Cardiovasc Drugs Ther. 2003;17:83-91. 
Sever P, Dahlof B, Poulter NR, Wedel H. Anglo-Scandinavian Cardiac Outcomes Trial: Lipid-Lowering Arm (ASCOT-LLA) revisited: interaction of antihypertensive and lipid lowering therapy. Circulation. 2005;112(Suppl. S):U188.

Speirs C, Wagniart F, Poggi L. Perindopril postmarketing surveillance: a 12 month study in 47351 hypertensive patients. Br J Clin Pharmacol. 1998;46:63-70.

Staessen JA, Wang J, Bianchi G, Birkenhager WH. Essential hypertension. Lancet. 2003;361:1629-1641.

Staessen JA, Birkenhäger WH. Evidence that new antihypertensives are superior to older drugs. Lancet. 2005;366:869-871.

Stoysich A, Massoomi F. Automatic interchange of the ACE inhibitors: decision-making process and initial results. Formulary. 2002;37:41-44.

Thuillez C, Mulder P, Elfertak L, et al. Prevention of endothelial dysfunction in small and large arteries in a model of chronic heart failure. Effect of angiotensin converting enzyme inhibition. Am J Hypertens. 1995;8:7S-12S.

Tropeano Al, Boutouyrie P, Pannier B, et al. Brachila pressure-independent reduction in carotid stiffness after long-term angiotensin-converting enzyme inhibtion in diabetic hypertensives. Hypertension. 2006;48:80-86.

Turnbull F; Blood Pressure Lowering Treatment Trialists' Collaboration. Effects of different blood-pressure-lowering regimens on major cardiovascular events: results of prospectively-designed overviews of randomised trials. Lancet. 2003;362:1527-1535.
Williams B, Poulter NR, Brown MJ, et al. Guidelines for management of hypertension: report of the fourth working party of the British Hypertension Society, 2004-BHS IV. J Human Hypertens. 2004;18:139-185.

Williams B. ASCOT - hold on to your horses! Br J Cardiol. 2005;12:336-338.

Williams IL, Chowienczyk PJ, Wheatcroft SB, et al. Divergent effects of angiotensin-converting enzyme inhibition on blood pressure and endothelial function in obese humans. Diab Vasc Dis Res. 2006;3:34-38.

Yusuf S, Sleight P, Pogue J, et al. Effects of an angiotensin-converting-enzyme inhibitor, ramipril, on cardiovascular events in high-risk patients. The Heart Outcomes Prevention Evaluation Study Investigators. N Engl J Med. 2000;342:145-153.

Zhou JL, Mendelsohn FA, Ohishi M. Perindopril alters vascular angiotensinconverting enzyme, AT(1) receptor, and nitric oxide synthase expression in patients with coronary heart disease. Hypertension. 2002;39:634-638.

Correspondence: Paul Chrisp, Core Medical Publishing, Mere House, Brook Street, Knutsford, Cheshire WA16 8GP, UK or at editor@coreevidence.com 